\title{
A Hydrogel Based Thermal Management System for Lithium-ion Batteries
}

by

Sijie Zhang

A thesis submitted to the Faculty of Graduate and Postdoctoral Affairs in partial fulfillment of the requirements for the degree of

\author{
Master of Applied Science \\ in
}

Materials Engineering

Carleton University

Ottawa, Ontario

(C) 2014

Sijie Zhang 


\begin{abstract}
Many portable devices such as soldier carried devices are powered by low-weight but highcapacity lithium ion (Li-ion) batteries. An effective battery thermal management (BTM) system is required to keep the batteries operating within a desirable temperature range with minimal variations, and thus to guarantee their high efficiency, long lifetime and great safety. In this study, a water based sodium polyacrylate (PAAS) hydrogel thermal management system is developed to handle the heat surge during the operation of Li-ion battery pack. This BTM system is tested through a series of high-intensity discharge and abnormal heat release processes, and its performance is compared with other classical BTM systems. The test results demonstrate that the developed low-cost, space-saving, and contour-adaptable BTM system is a very economic and efficient approach in handling the thermal surge of Li-ion batteries.
\end{abstract}




\section{Acknowledgements}

First and foremost, I would like to express my deepest gratitude to my supervisors: Prof. Junjie Gu and Prof. Jie Liu who made this research work possible. Without their patient guidance and enthusiastic supervision this thesis would not exist. They supported and guided me throughout the entire master program and always encouraged me to develop new ideas.

I also take this opportunity to express a deep sense of gratitude to all those who have improved the quality of this thesis and helped me in completing this task through various stages. I offer my profound appreciation for the valuable comments and suggestions provided by Dr. Zhonghua Zhang and Rui Zhao in the preparation of manuscripts of this work for journal publication.

My completion of this project could not have been accomplished without the support of my caring and loving parents. Their constant encouragement throughout the course of this thesis are much appreciated and duly noted.

Finally, the financial support from Natural Sciences and Engineering Research Council (NSERC) of Canada and battery supplement from Panacis Inc. are gratefully acknowledged. 


\section{Contents}

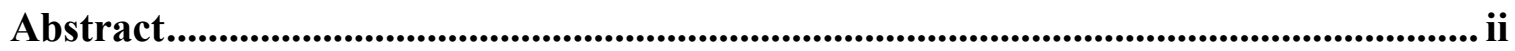

Acknowledgements .................................................................................................ii

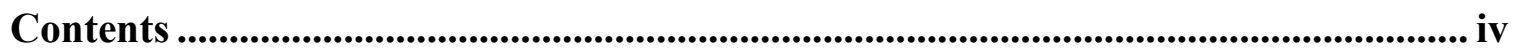

List of Tables ............................................................................................................................. vi

List of Illustrations..................................................................................................... vii

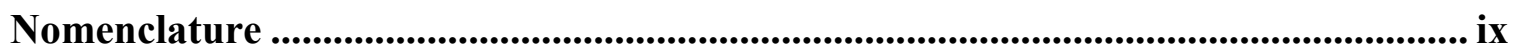

1 Chapter: Introduction ....................................................................................................... 1

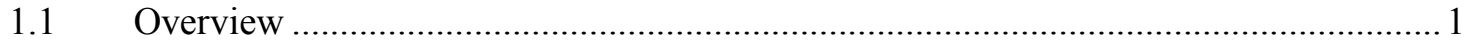

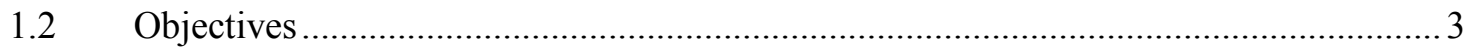

$1.3 \quad$ Thesis Outline

2 Chapter: Background and Literature Review ............................................................ 5

$2.1 \quad$ Lithium-ion Battery and the Thermal Issues ............................................................. 5

2.2 Battery Thermal Management System ................................................................. 8

2.2.1 Active Thermal Management System ............................................................. 8

2.2.1.1 Forced Air Cooling System ...................................................................

2.2.1.2 Liquid Active Cooling System ..................................................................... 12

2.2.2 Passive Thermal Management System................................................................... 13

2.2.2.1 Phase Change Material Cooling System …………….................................... 14

2.2.2.2 Passive Cooling with Heat Pipes .................................................................. 16

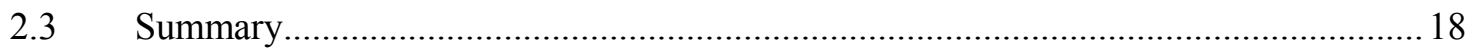

3 Chapter: The Evaluation of Hydrogel Thermal Management System in Cooling

Li-ion Battery under Normal Usage................................................................................... 20

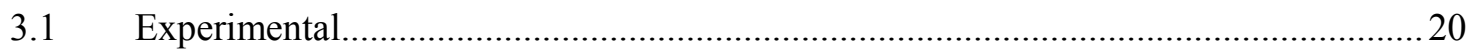


3.1.1 Comparison of Thermal Management Systems

3.1.2 Performance Evaluation of Hydrogel Thermal Management System in Short Term and Long Term

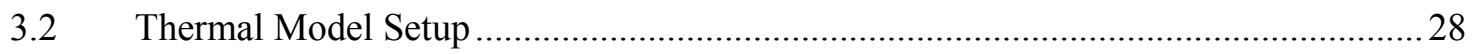

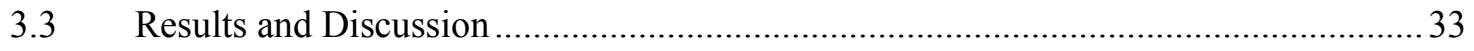

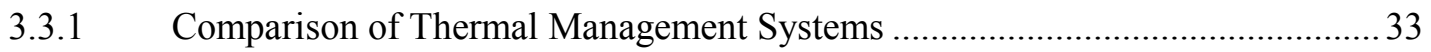

3.3.1.1 PAAS Hydrogel vs. Active Air-Cooling ........................................................ 38

3.3.1.2 PAAS Hydrogel vs. Traditional PCM ......................................................... 38

3.3.2 Hydrogel BTM system in High Rate CCD Test: Comparison of Experiment and

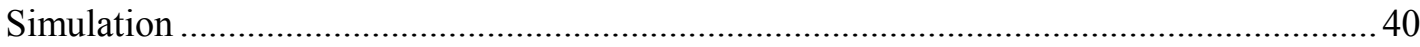

3.3.3 Effect of Hydrogel BTM system in CCD Tests at Various Discharge Rates....... 44

3.3.4 Hydrogel BTM system in Continuous Cyclic Safety Test ................................. 48

3.3.5 Hydrogel BTM system in Capacity Fading Test............................................... 51

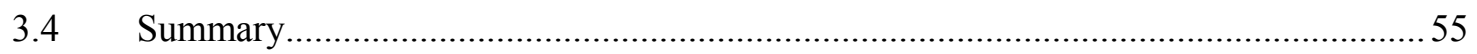

\section{Chapter: Evaluation of Hydrogel Thermal Management System under Abuse}

Condition .......................................................................................................................... 57

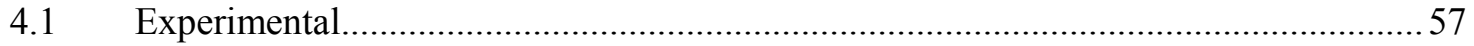

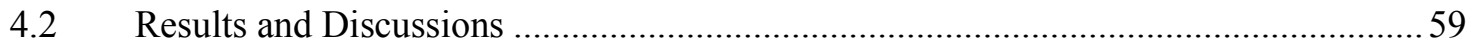

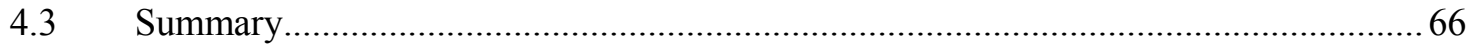

5 Chapter: Conclusions and Future Works.............................................................. 68

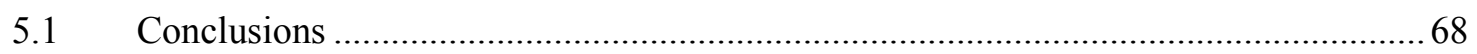

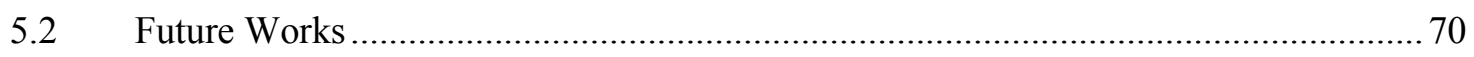

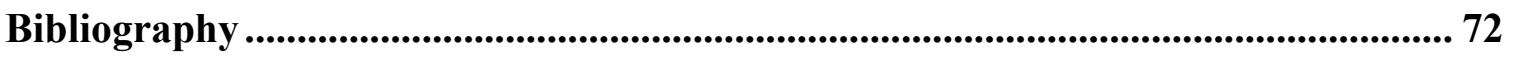




\section{List of Tables}

Table 1. Specifications of two battery packs. ........................................................... 21

Table 2. Specification of the cell components used in the simulation [23]................... 25

Table 3. Cell specification and the properties of PAAS hydrogel................................ 26

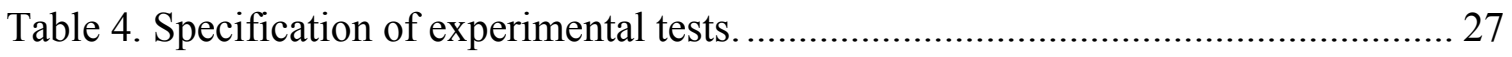

Table 5. Summary of the temperature rises at the center of battery modules during the discharge cycle at various C-rates in different BTM systems. .................................... 35

Table 6. Thermal properties of PAAS hydrogel and PCM used as battery thermal management materials in the discharge tests. ....................................................... 40

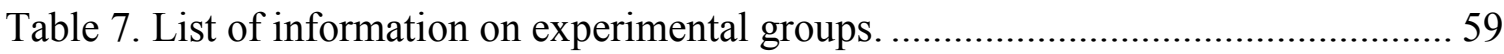

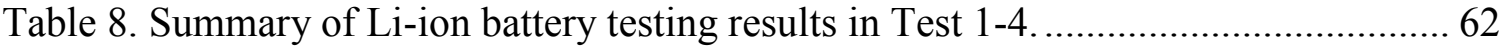

Table 9. Penetration results for the cells tested in the hydrogel thermal management system. 


\section{List of Illustrations}

Figure 2.1 (a) Multi-layered core configuration in a Lithium-ion polymer battery; (b) core of a single battery pack; (c) a unit cell of the battery including a pair of porous electrodes, a porous separator, and current collectors is shown during discharge process. The pores of polymer components, i.e., electrodes and separator are filled with an electrolyte liquid which allows transfer of ions between the electrodes [23] 7

Figure 2.2 A PHEV (plug-in hybrid electric vehicle) air-cooled module: (a) photograph of the existing module (courtesy of John Ireland of the U.S. Department of Energy's National Renewable Energy Laboratory), and (b) simplified computational domain with boundary conditions $[25]$ 10

Figure 2.3 a) Geometric configurations of the forced cooling manifolds; b) Temperature distributions in the five types of manifolds [14]. 12

Figure 3.1 Hydrogel thermal management system on $8000 \mathrm{mAh}$ battery pack. 22

Figure 3.2 Schematic illustration of the models used in thermal simulations: (a) battery pack with hydrogel BTM system; and (b) battery pack without BTM system 24

Figure 3.3 Internal resistance profile of 3 Ah battery pack under 10 A discharge rate with and without hydrogel BTM system...... 30

Figure 3.4 Temperature vs. time profiles of 1300 mAh battery pack with four BTM strategies in the discharge processes at discharge rates of (a) $1 \mathrm{C}$, (b) $2 \mathrm{C}$, and (c) 4 C. . 34 Figure 3.5 Temperature vs. time profile of $8000 \mathrm{mAh}$ battery pack with four BTM strategies in the discharge processes at a discharge rate of $1 \mathrm{C}$. 35

Figure 3.6 Temperature profiles for the 3 Ah battery pack at 10 A discharge current in both 
simulation and experiment, (a) without BTM system, (b) with hydrogel BTM system

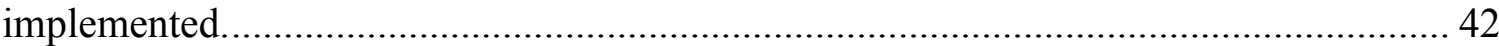

Figure 3.7 Numerical simulation profiles of temperature distribution inside battery pack w/wo hydrogel BTM system at the end of discharge. 44

Figure 3.8 Thermal response of the packs w/wo hydrogel BTM system at different

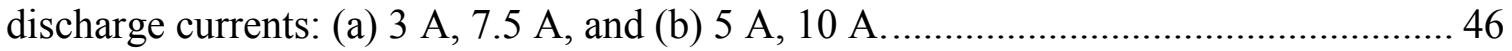
Figure 3.9 Temperature differences of two assigned points in the battery pack under different discharge rates (a) without BTM system and (b) with hydrogel BTM system.. 48 Figure 3.10 Four-cycle safety test of the battery pack under 7.5 A continuous charge and discharge process: (a) in ambient condition, (b) with hydrogel BTM system 50

Figure 3.11 Discharge voltage curves of the $2^{\text {nd }}$ cycle of the battery packs in ambient and in hydrogel BTM system. 53

Figure 3.12 Temperature profiles of the $2^{\text {nd }}$ discharge process of the battery packs w/wo hydrogel BTM system. 53

Figure 3.13 Capacity fading curves of the 5S 8 Ah battery packs in ambient condition and in hydrogel BTM system. $\left(\mathrm{T}_{\mathrm{amb}}: 30^{\circ} \mathrm{C}, \mathrm{I}_{\text {discharge }}=\mathrm{I}_{\text {charge-max }}=8 \mathrm{~A}\right)$. 54 Figure 4.1 Schematic illustration of two penetration systems: (a) heavy system and (b) light system. 58

Figure 4.2 Photograph of a seriously damaged cell penetrated by a wooden nail. 61

Figure 4.3 Photograph of a sample cell penetrated in hydrogel BTM system. 63 Figure 4.4 Schematic diagram of the motion of ions and electrons in adjacent electrodes after penetration. 65 


\section{Nomenclature}

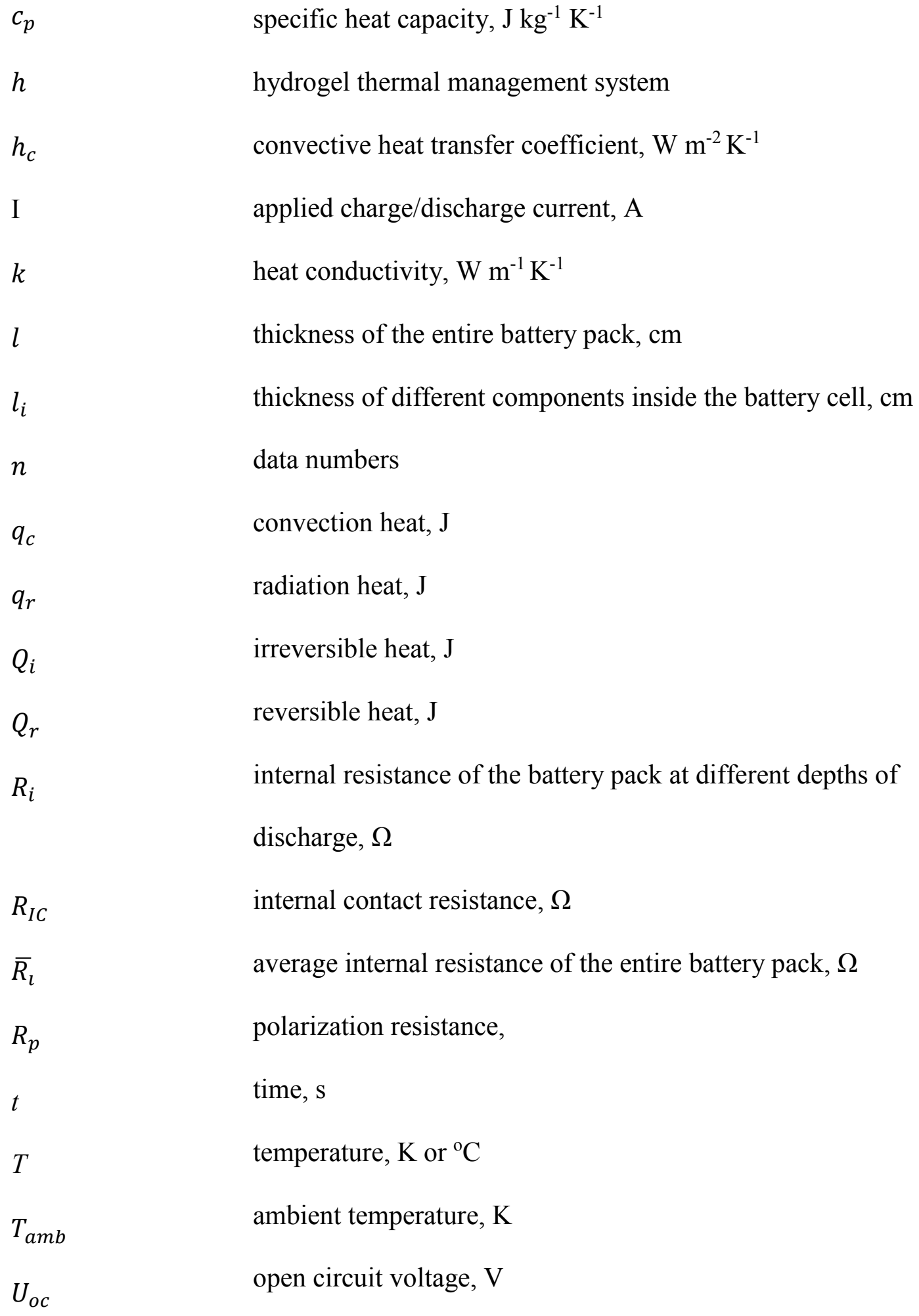

$c_{p}$

$h$

$h_{c}$

I

$k$

$l$

$l_{i}$

$n$

$q_{c}$

$q_{r}$

$Q_{i}$

$Q_{r}$

$R_{i}$

$R_{\text {IC }}$

$\bar{R}_{l}$

$R_{p}$

$t$

$T$

$T_{a m b}$

$U_{o c}$

specific heat capacity, $\mathrm{J} \mathrm{kg}^{-1} \mathrm{~K}^{-1}$

hydrogel thermal management system

convective heat transfer coefficient, $\mathrm{W} \mathrm{m} \mathrm{m}^{-2} \mathrm{~K}^{-1}$

applied charge/discharge current, A

heat conductivity, $\mathrm{W} \mathrm{m} \mathrm{m}^{-1} \mathrm{~K}^{-1}$

thickness of the entire battery pack, $\mathrm{cm}$

thickness of different components inside the battery cell, $\mathrm{cm}$

data numbers

convection heat, $\mathrm{J}$

radiation heat, $\mathrm{J}$

irreversible heat, $\mathrm{J}$

reversible heat, $\mathrm{J}$

internal resistance of the battery pack at different depths of

discharge, $\Omega$

internal contact resistance, $\Omega$

average internal resistance of the entire battery pack, $\Omega$

polarization resistance,

time, $s$

temperature, $\mathrm{K}$ or ${ }^{\circ} \mathrm{C}$

ambient temperature, $\mathrm{K}$

open circuit voltage, $\mathrm{V}$ 
$\varepsilon_{\mathrm{e}}$ mass content of PAAS particles

emissivity

density of different components inside the battery cell, $\mathrm{kg} \mathrm{m}^{-3}$ 


\section{Chapter: Introduction}

\subsection{Overview}

Lithium ion (Li-ion) batteries have emerged as the most promising energy storage technology in recent years due to their higher energy density, lighter weight, no memory effect, and lower self-discharge rate, when compared to other rechargeable battery technologies [1]. Although offering many advantages and benefits, the rigorous requirement for the compactness of Li-ion battery packs in many critical applications (e.g., aerospace and military) usually makes it difficult for the implementation of classical battery thermal management (BTM) systems and often gives rise to some safety issues such as overheating or thermal runaway [2]. Even in safe operation, any increase in temperature may significantly shorten the lifecycles of batteries [3-7]. Therefore, a compact and robust BTM system is critically needed to minimize the temperature rise of Li-ion batteries.

In general, a BTM system can be implemented using either an active cooling system or a passive cooling system. The active cooling system is typically achieved by using fans or pumps to circulate coolants (air [8-10], liquid [11], or $\mathrm{CO}_{2}[12,13]$, etc.) so that the heat can be extracted from the battery packs. For example in Refs. $[14,15]$, the temperature distribution in battery packs was modified by the forced air convection. The batteries with various types of cell arrangements were designed and the energy consumption was formulated as a function of the pressure drop between the inlet and outlet, from which the optimized arrangements of cells and air flow rates can be obtained. Also the study in Ref. [16] demonstrated the effectiveness of water-ethylene glycol mixture in controlling the temperature of battery pack through the implementation of a constant temperature bath. 
The spatial and temporal temperature variations during the course of discharge were maintained within $0.5^{\circ} \mathrm{C}$, but the mobility of the liquid used as coolant may cause safety issues, such as the short circuit, in practice. Generally, a reasonable cell arrangement, a well-designed circulation system, and a powerful cooling material are essential in an active cooling system; however, these elements may also make the system much bulky and power-demanding, which restricts its application in portable battery packs (e.g., soldierworn battery packs). The passive cooling system makes good use of the physical properties of various coolants implemented between neighboring battery cells to absorb the heat released during the operation, thereby keeping the battery temperature at a relatively low level. The present passive cooling systems usually rely on phase change materials (PCM) for heat absorption. Al Hallaj has first introduced the PCM to thermal management system for the 18650 battery pack [17]. In his study, the temperature of cells and the temperature distribution across the battery pack were inspected at various depths of discharge, and the comparison with air cooling showed the effectiveness of PCM in battery temperature control. However, the PCM material based passive thermal management system often suffers from the following three inherent limitations: 1) high melting point of the PCMs. The relevant battery cells need to reach the melting points (typically higher than $40^{\circ} \mathrm{C}$ ) of PCMs to utilize their phase change properties. Such high temperature will shorten the life span of the battery; 2) low specific heat capacity of the PCMs (both solid state and liquid state). This will lead to the dramatic rise in the temperature of the battery pack when the PCM temperature is below the melting range; and 3) poor thermal conductivity of the PCMs. This often results in slow heat dissipation and uneven heat distribution, which is extremely harmful to the health of the battery pack and may even lead to an explosion [18, 
19]. Although various strategies for PCM matrix optimization based on the PCM/graphite mixture have been reported in recent years [20,21], which can provide higher thermal conductivity, the specific heat capacity of the PCM matrix will in turn be significantly reduced (below $2 \mathrm{~kJ} \mathrm{~kg}^{-1} \mathrm{~K}^{-1}$ ) when inserted into the graphite. Moreover, the preparation of the $\mathrm{PCM} /$ graphite matrix is usually a time-consuming and costly process.

\subsection{Objectives}

To develop a novel passive cooling system to overcome the limitations associated with the classical PCMs, a flexible hydrogel-based BTM system is developed in this thesis. The developed system is based on sodium polyacrylate (PAAS) hydrogel, which possesses the following advantages: 1) low cost and high flexibility. PAAS is a type of polymer that has been widely used in daily life for liquid absorption (e.g., diapers). The PAAS-based hydrogel is usually of low cost and can be flexibly packed to accommodate any shapes of battery packs; 2) strong water absorbing capacity. Owing to a great number of hydrophilic groups in the three-dimensional chemical chains, the PAAS polymer has the ability to absorb as much as hundreds of times its mass in water. On one hand, the absorbed water is superior in heat control thanks to its high sensible heat absorption capacity; and on the other hand, the mobility of water can be well managed in operation; and 3) simple and controllable manufacturing process. The performance of the developed BTM system is compared with other conventional BTM systems. The testing results demonstrate that the developed hydrogel-based BTM system is more effective than the other BTM systems in keeping battery packs' temperature stable within an allowable range in discharge tests and preventing the occurrence of thermal runaway in penetration tests. 


\subsection{Thesis Outline}

The following text is divided into five main parts. Chapter 2 provides a state-of-theart review on Lithium-ion battery, the thermal issues involved in the operation of the battery and classical thermal management systems for Li-ion battery pack. Chapter 3 shows the effectiveness of the developed hydrogel thermal management system in controlling the temperature rise of Li-ion battery at various operating conditions through both experiments and simulations. Chapter 4 deals with the nail penetration tests, which are performed on Li-ion battery cells under different cooling conditions, and it is shown that the developed PAAS hydrogel cooling system can effectively suppress the occurrence of thermal runaway. Finally, the conclusions of this thesis and some future research topics are presented in Chapter 5. 


\section{Chapter: Background and Literature Review}

When studying a new battery technology, the first important step is to understand the internal structure and working mechanism of the battery and the inherent safety issues relevant to it. This chapter contains three sections. Section 2.1 introduces the structure of Lithium-ion battery (Li-ion battery) cell and how it works, and also illustrates that the overheating problem, a major safety concern of using Li-ion battery, can be resolved by implementing BTM system. Then in Section 2.2, the advantages and disadvantages of different BTM systems are analyzed on the basis of an extensive literature review. For example, the application of active BTM system can be limited by its high power and space demand. Finally, some concluding remarks are summarized in the last section.

\subsection{Lithium-ion Battery and the Thermal Issues}

Lithium-ion (Li-ion) batteries are comprised of battery cells that employ lithium intercalation and de-intercalation compounds as electrode materials. During the operation of Li-ion battery, the charged Li-ions exchange between anodes and cathodes. The Li-ion battery is also known as the rocking-chair battery because the Li-ions go back and forth between the two electrodes [22]. The most common Li-ion batteries are $\mathrm{LiCoO}_{2}$ battery and $\mathrm{LiMnO}_{4}$ battery, and the $\mathrm{LiCoO} 2$ battery is the one that is relatively thermally unstable. It degrades fast at high temperature and has the potential to cause safety issues at high temperature. However, the high energy density of $\mathrm{LiCoO}_{2}$ battery makes it more commonly 
used. Thermal management system is needed in this kind of battery, which is, in turn, generally used to test the effectiveness of different thermal management systems.

The schematic illustrations of a Li-ion battery and its electrochemical reaction cell are shown in Fig. 2.1. In each reaction cell five components are consisted: aluminum current collector, positive electrode (cathode), separator, negative electrode (anode) and copper current collector. During discharge, lithium ions de-intercalate from the anode and pass the separator to react with the electrons flowed through the external circuit and intercalate into the cathode. Reverse reaction takes place during the charging process. 

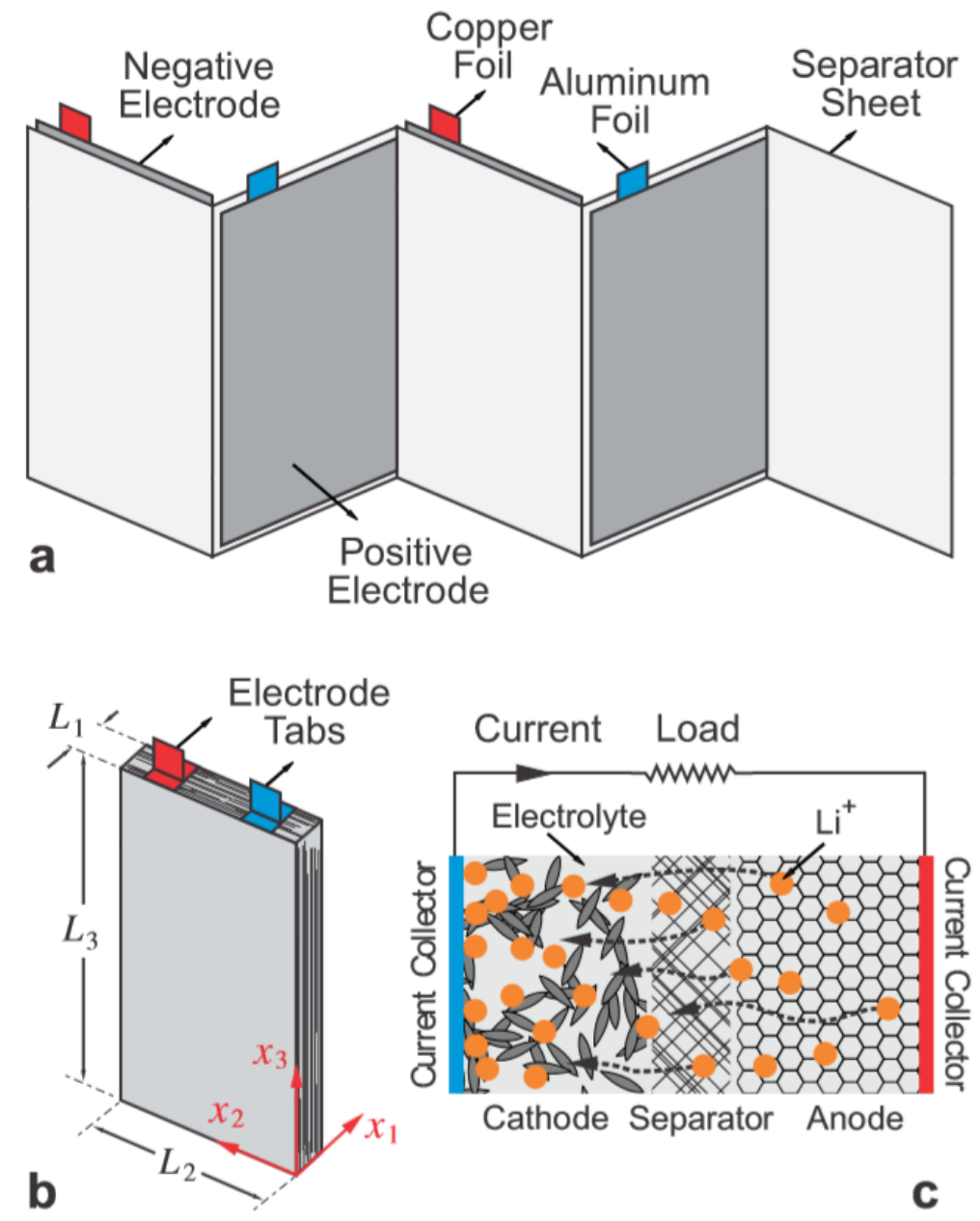

Figure 2.1 (a) Multi-layered core configuration in a Lithium-ion polymer battery; (b) core of a single battery pack; (c) a unit cell of the battery including a pair of porous electrodes, a porous separator, and current collectors is shown during discharge process. The pores of polymer components, i.e., electrodes and separator are filled with an electrolyte liquid which allows transfer of ions between the electrodes [23].

Safety is a key issue for all kinds of energy storage devices, and Li-ion battery is no exception. However, the safety issue in Li-ion battery should be more concerned than in other devices since the battery cell contains both oxidizer (cathode) and fuel (anode) [24]. Generally, during the operation of Li-ion battery, the heat generated is mainly divided into 
two parts: irreversible heat and reversible heat. Irreversible heat is generated due to the difference between the open circuit potential and the actual potential, while reversible heat is produced by the entropy changes of anode materials and cathode materials during operation.

During normal operation, the lithium in cathode and anode exchanges to generate the energy needed to supply electrical devices. In abnormal conditions, such as internal short circuit and external short circuit, the cathode and anode may contact directly and the reaction may complete in a very short period of time, with a great amount of heat and gas produced inside the battery, which may finally lead to the failure of the battery, and even the entire battery pack. In this case, the heat generated includes more than reversible heat and irreversible heat. The main heat produced during the failure, which causes thermal runaway, is from the combustion of cathodes, anodes and separators. To avoid the occurrence of thermal runaway, a proper thermal management system should be developed to avoid the battery from overheating, which may lead to chain reactions of the internal materials. Section 2.2 gives a brief introduction to the BTM systems mostly researched in recent years.

\subsection{Battery Thermal Management System}

\subsubsection{Active Thermal Management System}

Active thermal management systems, the most commonly used BTM system today, typically utilize the circulation of heat absorbing materials, most commonly air or liquid, to remove the heat produced during the operation of devices. The advantage of this type of thermal management system is that it can intelligently control the temperature of the device 
by adjusting the circulation speed and other parameters according to the real-time condition. However, the consumption of power and space may limit its usage in some real world applications. In this section, two types of active cooling systems are introduced, and brief descriptions of a number of relevant studies are also provided to help understand these BTM systems.

\subsubsection{Forced Air Cooling System}

Forced air cooling is generally realized by blowing air through the operating battery pack to take heat away, thereby cooling the batteries. Fan et al. investigated the impact of battery gap distance and air flow velocity on the effectiveness of forced air cooling system, which is indicated by the temperature of Li-ion battery pack operating in HEVs [25]. In this work, three-dimensional simulations were performed to study the exothermic behavior of the Li-ion battery pack module, with the heat generation rate set at $28000 \mathrm{~W} \mathrm{~m}^{-3}$ for the entire battery pack. And the thermophysical properties of a commercial 15 Ah cell were employed in this modeling effort.

In the original case (Figure 2.2), with the gap distance between cells of $3 \mathrm{~mm}$ and the air flow rate of $20.4 \mathrm{~m}^{3} \mathrm{~h}^{-1}$, the results of simulation showed that the maximum temperature rise within the eight cells' pack was approximately $6.53^{\circ} \mathrm{C}$, which was found at the middle cell. The cells on both sides of the pack had relatively lower temperature difference of about $2.4^{\circ} \mathrm{C}$, while the temperature difference of the middle cell nearly reached $3^{\circ} \mathrm{C}$. Then, the gap spacing between cells was either increased $(\mathrm{d}=4$ or $5 \mathrm{~mm})$ or reduced $(\mathrm{d}=1$ or 2 $\mathrm{mm})$. It was found that as the gap spacing increased from $1 \mathrm{~mm}$ to $5 \mathrm{~mm}$, the maximum temperature rise within the eight cells grew by about $0.77^{\circ} \mathrm{C}$, yet with a simultaneous 
favorable compensation that the temperature difference between cells decreased by $0.41^{\circ} \mathrm{C}$. The impact from air flow rate was then studied by changing the flow rate while keeping the gap spacing at $3 \mathrm{~mm}$. By varying the flow rate from 10.2 to $40.8 \mathrm{~m}^{3} \mathrm{~h}^{-1}$, the maximum temperature rise reduced by about $3.3^{\circ} \mathrm{C}$, and the corresponding improvement of the uniformity was $0.2^{\circ} \mathrm{C}$.

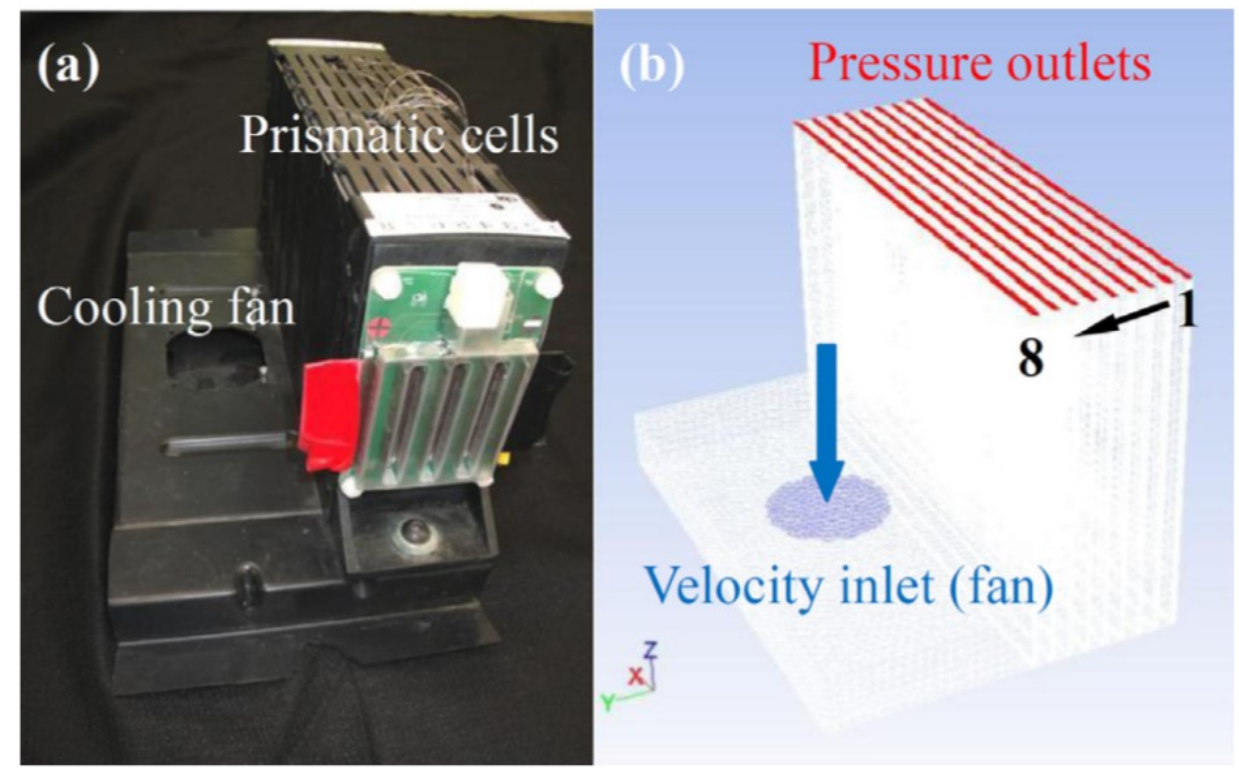

Figure 2.2 A PHEV (plug-in hybrid electric vehicle) air-cooled module: (a) photograph of the existing module (courtesy of John Ireland of the U.S. Department of Energy's National Renewable Energy Laboratory), and (b) simplified computational domain with boundary conditions [25].

The combined impact from gap spacing and air flow rate was studied through the maximum temperature and temperature uniformity obtained inside the battery pack. A conclusion was drawn that slighter temperature rise within the battery pack could be approached by narrowing the gap and increasing the flow rate of fan, while a better temperature uniformity over the entire pack would be achieved in the battery pack managed 
with moderate gap spacing and high air flow rate. The trade-off between the maximum temperature increase and temperature uniformity should be considered when designing the battery pack configuration and the specifications of battery cooling system. Note that uneven gaps between cells can provide a more uniform cooling for the cells within the module without changing the maximum temperature rise.

The ideal power consumption of different cooling cases was investigated based on the equation: Power $=\Delta \mathrm{P} \times \mathrm{V}$, where $\Delta \mathrm{P}$ is the pressure drop across the cooling fan and $\mathrm{V}$ is the volumetric air flow rate. The ideal fan power required was low when the gap spacing was increased while the air flow rate was kept constant, but it increased when the air flow rate rose at a constant gap spacing. One-side cooling was also studied in this paper by placing a non-conductive thin separator in the middle of neighboring cells. This cooling method was less effective compared to the two-side cooling, but it was more spacing saving.

Park examined the effect of air flow design on the cooling effectiveness and power consumption of forced air cooling system [14]. The battery pack under study consisted of 72 cells in two rows with a capacity of $1400 \mathrm{Wh}$ and an operating voltage of $270 \mathrm{~V}$. The gaps between cells were $3 \mathrm{~mm}$ and unchangeable. In total, five types of air flow design were investigated, as shown in Fig. 2.3a. Air flow rate, velocity distribution, pressure distribution and thermal resistance of the five types of configurations were studied. The simulation results were presented in Fig. 2.3b. The first three types of configurations were not practically applicable due to the high calculated pressure drops, which are beyond the fan operation limit. In the rest two types of configurations, the power consumptions of the fan were estimated to be $47 \mathrm{~W}$ and $27 \mathrm{~W}$, respectively, and the use of the last type could dramatically decrease the risk of over heat of the battery pack with an optimized energy 
utilization.

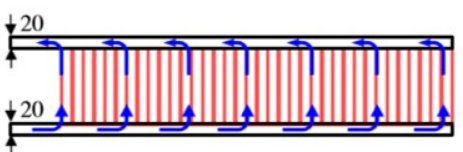

(a)

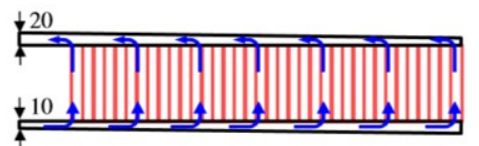

(b)

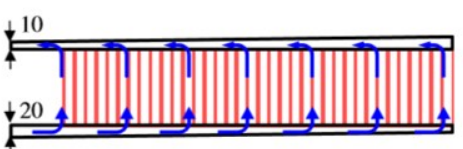

(c)

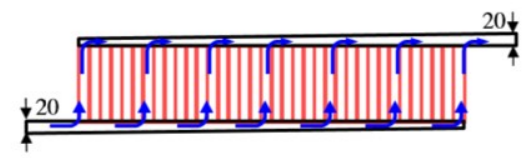

(d)

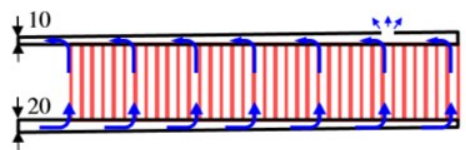

(e)

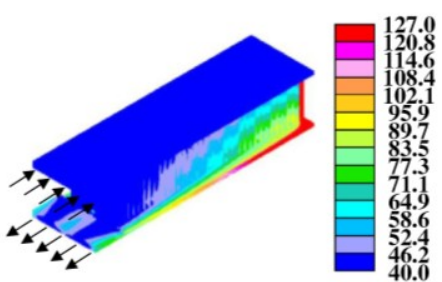

(a) Type I

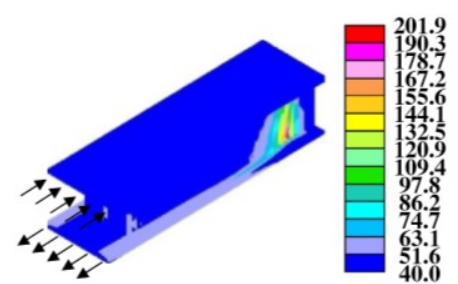

(b) Type II

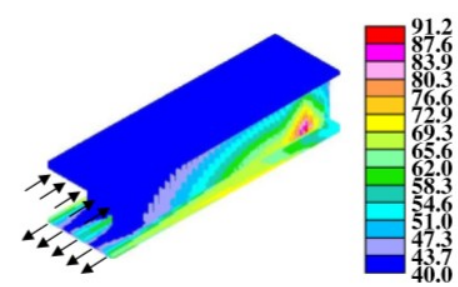

(c) Type III

b)

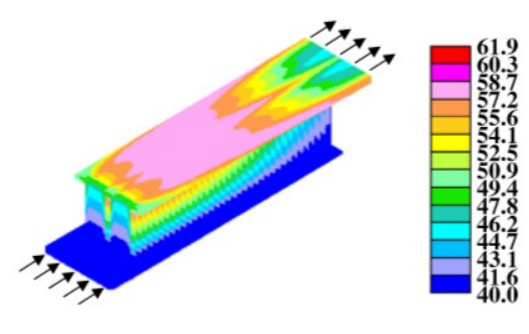

(d) Type IV

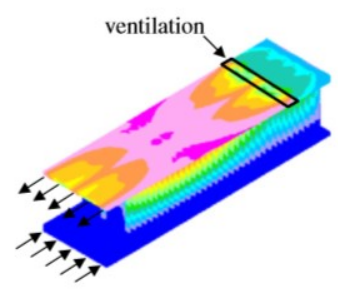

(e) Type V

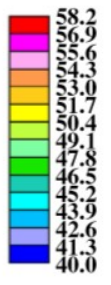

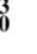

Figure 2.3 a) Geometric configurations of the forced cooling manifolds; b) Temperature distributions in the five types of manifolds [14].

\subsubsection{Liquid Active Cooling System}

Liquid materials are circulated to remove heat from battery pack in liquid active cooling system. A PCM based slurry was proposed by Zhang et al. for actively cooling the batteries in EVs [26]. Three types of active cooling methods, direct cabin air flow, PCM 
slurry cycle and refrigerant circulation, were compared and evaluated. Paraffin octadecane $\left(\mathrm{C}_{18} \mathrm{H}_{37}\right)$ and pentadecane $\left(\mathrm{C}_{15} \mathrm{H}_{31}\right)$ were the PCM used and were identified to be suitable heat transfer mediums for battery cooling and heating, respectively. Compared with cabin air cooling, the PCM slurry circulation and refrigerant circulation systems had more stable cooling power loads at various humidity conditions and ambient temperatures. When battery operated with high heat generation rates, the direct cabin air blow method caused more cooling load than that of the other two methods.

Thermodynamic analysis was also carried out with the three active cooling systems. More exergy had to be supplied to the direct cabin air blow system than to the other two systems to cool or heat the battery when the ventilation air is not included. Provided certain amount of exergy, refrigerant cooling system wasted $80 \%$ of it by exchanging heat between refrigerant evaporator and battery cooling air. Whereas in the PCM slurry cycle, the heat exchange only consumed $60 \%$ of the total input exergy, but the power consumption of PCM slurry cycle still needed further estimation.

Overall, the direct cabin air flow required less or even no extra cooling or heating supply when the cabin ventilation air was included for battery cooling or heating. However,

its extra thermal load grew faster than others when the battery cooling or heating load increased. The thermodynamic 2nd law analysis proved that the exergy efficiency of the PCM slurry cycle is higher than that of the refrigerant circulation system.

\subsubsection{Passive Thermal Management System}

Compared with active thermal management system, passive system is lighter, more compact, more energy efficient and easier to manufacture. This part introduces two types 
of most common passive cooling systems: phase change material (PCM) cooling system and heat pipe cooling system.

\subsubsection{Phase Change Material Cooling System}

Al-Hallaj and Selman firstly proposed PCM to be used in thermal management system for EVs [27]. A commercial finite element software was used to simulate the thermal behavior of EV battery modules in their study. Paraffin wax, which has an appropriate melting range, was chosen as the material absorbing the generated heat. The battery module in the simulation had eight cells assembled in series with the capacity of each cell of 100 Ah. Energy balance equation was developed to describe the thermal behavior of the battery module, in which the thermal property of PCM was assigned different values at different states: solid phase, mushy phase and liquid phase. The results obtained from the simulation were well consistent with the data from experiment.

The effect of PCM in cooling discharging batteries was compared with the air cooling method with different heat-transfer coefficients set, and their effectiveness was suggested by the temperature rise and temperature distribution along the axial and radial directions of 18650 battery and 100 Ah battery. The air cooling system was effective at low cooling rate, which was demonstrated by the even distribution of temperature across the cells, but when high heat-transfer coefficient was used, the temperature distribution along the diameter became uneven, and the temperature difference between the cell surface and center was significant at all depths of discharge. After introducing PCM to the battery pack, 
the temperature rise inside the battery pack greatly decreased due to the endothermic behavior of PCM during phase change period.

Khateeb et al. developed an aluminum matrix for PCM thermal management system and experimentally tested the improvement of the proposed system [28]. In total, four types of cooling systems were compared: PCM cooling system, Al-foam system, PCM \& Alfoam system and natural air cooling system (i.e., ambient condition). 4S6P (four cells in series and six strings in parallel) and 3S6P 18650 battery packs were used in the experiment.

Among the four cooling systems, the batteries in ambient condition had the largest temperature increase due to the lack of heat absorbing material, therefore a proper thermal management system played an important role in the safety and health of battery. In the other three systems, the aluminum cooling system performed the worst, which was mainly attributed to the low specific heat capacity of Al-foam. When PCM was utilized as thermal management system, a large drop in the temperature rise was observed. However, the poor thermal conductivity of PCM resulted in slow heat dissipation to the surroundings, which might lead to complete melting of PCM during abusive operation of battery and could not prevent the dramatic temperature increase afterwards. By implementing aluminum matrix, the overall thermal conductivity of the original PCM thermal management system increased, and thus it could be used even in hot summer condition.

Kizilel et al. studied the passive thermal management system based on PCM with graphite matrix [29]. This work compared the temperature increase in 8S2P packs with and without PCM and the temperature uniformity along the packs at room temperature. The degradation rates of 4S4P battery packs with and without PCM system were examined. 
Also, the thermal and electrochemical performance of 7S2P packs at normal and stressed conditions were studied.

In the proposed PCM cooling system, the thermal conductivity of PCM was significantly improved due to the involvement of graphite. During the discharge process, the temperature of the $8 \mathrm{~S} 2 \mathrm{P}$ battery pack increased to about $40^{\circ} \mathrm{C}$, then the PCM started to melt, absorbing a lot of heat, while the pack without PCM experienced a dramatic increase in temperature. Also, the temperature difference between cells decreased from $10^{\circ} \mathrm{C}$ to $4^{\circ} \mathrm{C}$ for the battery pack equipped with the PCM system, which was beneficial to the long-term health and performance of battery pack. Then the discharge curves of 4S4P battery pack in two systems were compared. At the beginning of the long term test, the pack without PCM cooling system exhibited a higher capacity output. The initial discharge capacities of the battery packs were measured to be $94 \%$ and $88 \%$ of the nominal capacity without PCM and with PCM, respectively, which was attributed to the smoother transportation of electrons and ions essential to electrochemical reactions at relatively higher operating temperature. However, after 300 cycles, it was found that the capacity fading of the pack without PCM became much more serious than that of the one with PCM. Under stressed condition, with the upper cut-off temperature set at $85^{\circ} \mathrm{C}$, the $7 \mathrm{~S} 2 \mathrm{P}$ battery pack without PCM cooling system reached the temperature limit first with only a small part of its nominal capacity used. After introducing the PCM cooling system, more than $90 \%$ of the nominal capacity was able to provide.

\subsubsection{Passive Cooling with Heat Pipes}

Tran et al. investigated the feasibility of flat heat pipe in mitigating the temperature 
increase during the operation of Lithium-ion battery used in HEV and EV [30]. Instead of directly using the battery module as the heat source for experiment, in this study, the heat flux generated from battery was reproduced through a flat heater and then applied to the flat heat pipe cooling system.

Two types of heating schemes were applied to the cooling system: constant input power and transient input power. When constant input power was used, the power was calculated from the heat profile generated from the battery cell during operation. When transient input power was utilized, the output power of the induction generator could be piloted between $10 \%$ and $100 \%$ of its maximum capacity using a $0-10$ Volt controller. Other than the experiment, a numerical battery module was built to simulate the thermal behavior inside the battery pack based on energy balance equations. The thermal performance of the cooling system was quantified by the thermal resistance used in the experiment (R1) and the thermal resistance of the entire cooling system for the battery module built in the simulation (R2).

Comparison was made between the effectiveness of heat pipe cooling system and heat sink cooling system. When the heat pipe was placed horizontally, the performance of heat pipe system was better than the cooling system equipped with heat sink, especially in natural convection condition. And the calculated R1 and R2 in the heat pipe system were $25^{\circ} \mathrm{C} \mathrm{W}^{-1}$ and $0.332^{\circ} \mathrm{C} \mathrm{W}^{-1}$, far less than those in the heat sink cooling system, $36^{\circ} \mathrm{C} \mathrm{W}^{-1}$ and $0.48^{\circ} \mathrm{C} \mathrm{W}^{-1}$. It was interesting that the heat sink cooling system performed better than the heat pipe cooling system in forced convection conditions, particularly at the air flow rate higher than $0.5 \mathrm{~m} \mathrm{~s}^{-1}$. The main reason was that the phase change of water inside the pipe did not occur when the temperature was lower or equal to $29^{\circ} \mathrm{C}$. Then tests were 
conducted with the heat pipe inclined at different angles. The results showed that the flat heat pipe worked efficiently under different grade road conditions, and the differences between horizontal and vertical positions were very small and could be neglected.

Rao et al. experimentally studied the cooling performance of copper tube heat pipe whose condensation section was cooled by a water module [31]. The whole cooling system was effective, as the maximum temperature of the controlled battery could be kept below $50^{\circ} \mathrm{C}$ when the heat generation rate of the battery pack was lower than $50 \mathrm{~W}$ and the maximum temperature difference inside the battery pack was maintained within $5^{\circ} \mathrm{C}$ when the heat generation rate was lower than $30 \mathrm{~W}$. Meanwhile, the heat pipe cooling system was able to control the temperature of the battery pack in unsteady conditions and cycling tests.

\subsection{Summary}

Lithium ion battery has a clear structure that consists of a number of single electrochemical reaction cells, and each reaction cell is composed of positive and negative electrodes attached on respective current collectors, and their separator. During the operation of Li-ion rechargeable battery, lithium ions migrate between the anode and the cathode and produce electrons through the intercalation/de-intercalation reactions.

To date, the safety issue about Li-ion battery has already caused many hazards. The excessive heat generated by Li-ion battery during abnormal operations or under mechanical abuse conditions can not only destroy the battery itself and the electrical device, but can also damage the surroundings and may even hurt people who is using or carrying the device. Even though the overheating is not triggered, the temperature increase of battery is still 
very harmful because it influences the charge acceptance, availability of discharge power and life of the battery, which further affect the performance and economy of the electrical device. Therefore, ideally, batteries should operate within a temperature range that is optimum for their performance and health [51].

In view of this, numerous BTM systems have been developed and researched in recent years. An optimum BTM system design should consider the tradeoffs between cost, performance, mass, volume, safety and maintenance. Particularly, the BTM system to be applied in HEV or soldier-carrying packs should be lightweight, compact, reliable, easily packaged, easily accessible for maintenance, and compatible with location in the vehicle or pack.

The BTM system mostly researched recently can be mainly categorized into active BTM system and passive BTM system based on whether power is needed or not. Active BTM system consumes power to circulate air, liquid, phase change material, or any combination to remove heat, while passive cooling method takes advantage of the characteristics of heat transfer medium, such as the latent heat absorption property of PCM during its phase change period, to dissipate heat without power consumption. Because of the circulation, active cooling system generally performs more efficiently than passive one in controlling the temperature rise in the battery, however, due to cost, mass, and space considerations, battery packs used in applications with strict weight and/or space limits tend to depend more on passive BTM system. 


\section{Chapter: The Evaluation of Hydrogel Thermal Management System in Cooling Li-ion Battery under Normal Usage}

In this study, a novel hydrogel based passive thermal management system for Lithium ion battery is developed. The hydrogel can be produced by simply adding PAAS powder to water at room temperature. The powder swells in water and the formed hydrogel has high moisture content as well as great viscosity, which means it possesses all the beneficial characteristics of water, such as the high specific heat capacity, and in the meantime avoids the mobility that is unfavorable for passive BTM system.

The evaluation of a BTM system should be conducted under both normal and abuse conditions. This chapter mainly deals with the normal testing. First of all, the functionality of hydrogel BTM system is compared with three classical cooling methods: forced air

cooling, PCM passive cooling and natural convection cooling. Then its effectiveness in cooling Li-ion batteries under different operating modes and reducing the fading rate of the batteries is validated.

\subsection{Experimental}

\subsubsection{Comparison of Thermal Management Systems}

Hydrogel BTM system used in the experiments is obtained by directly injecting deionized water into the battery cell module with the PAAS particles evenly distributed. The solid state hydrogel formed instantly due to the high hydroscopicity of PAAS, and the mass content of water in PAAS hydrogel is as high as $98 \%$. To ensure the safety of battery pack 
using hydrogel, the electrical resistivity of the PAAS hydrogel is measured, and the value is greater than $10 \mathrm{M} \Omega^{*} \mathrm{~cm}$, which is high enough to withstand the electric field in the battery pack.

Two $1300 \mathrm{mAh}$ and five $8000 \mathrm{mAh}$ pouch Li-ion cells are selected to construct two battery packs in the constant current discharge tests, in which the cells are connected in series and the space between neighboring cells are half the thickness of the cell. Table 1 lists the specifications of two battery packs. Four BTM systems (i.e., PAAS hydrogel, traditional PCM (paraffin wax), air-cooling, and natural convection) are built for the cell packs. The tests are performed in cardboard boxes with a dimension of $29.5 \mathrm{~cm} \times 11.5 \mathrm{~cm}$ $\times 11.5 \mathrm{~cm}$ in length, width, and height, respectively, to simulate the real circumstances, and every battery pack is placed at the center of each box.

Table 1. Specifications of two battery packs.

\begin{tabular}{lll}
\hline & Pack 1 & Pack 2 \\
\hline Pack operating & $3.0-4.2 \mathrm{~V} \mathrm{cell}^{-1}(6-8.4 \mathrm{~V}$ & $3.0-4.2 \mathrm{~V} \mathrm{cell}^{-1}(15-21 \mathrm{~V}$ \\
voltage & pack $\left.^{-1}\right)$ & pack $\left.^{-1}\right)$ \\
Pack capacity & $1300 \mathrm{mAh}$ & $8000 \mathrm{mAh}$ \\
Total weight of pack & & \\
Ambient & $58.7 \mathrm{~g}$ & $926.75 \mathrm{~g}$ \\
Hydrogel & $70.6 \mathrm{~g}$ & $1178.02 \mathrm{~g}$ \\
PCM & $68.66 \mathrm{~g}$ & $1146.24 \mathrm{~g}$ \\
Cooling fan & $240.32 \mathrm{~g}$ & $1108.37 \mathrm{~g}$ \\
Spacing between cells & $2 \mathrm{~mm}$ & $4.5 \mathrm{~mm}$ \\
Discharge rate & $1 \mathrm{C}, 2 \mathrm{C}, 4 \mathrm{C}$ & $1 \mathrm{C}$ \\
\hline
\end{tabular}


Fig. 3.1 shows the 8000 mAh battery pack with hydrogel coolant embedded in. The specific capacity and heat conductivity of the hydrogel are expressed as follows:

$$
\begin{gathered}
C p_{g e l}=\varepsilon C p_{P A A S}+(1-\varepsilon) C p_{H_{2} O} \\
k_{g e l}=\varepsilon k_{P A A S}+(1-\varepsilon) k_{H_{2} O}
\end{gathered}
$$

where $C p$ is the specific heat capacity, $k$ is the heat conductivity, and $\varepsilon$ is the mass content of PAAS particles. As for the PCM cooling system, the battery cells are inserted into the paraffin wax matrix. The air-cooling thermal management is achieved by placing a cooling fan of $8 \mathrm{~cm} \times 8 \mathrm{~cm}$ at one side of the battery pack with a distance of $5 \mathrm{~cm}$, and the rotation speed of the fan is set at $1500 \mathrm{rpm}$.

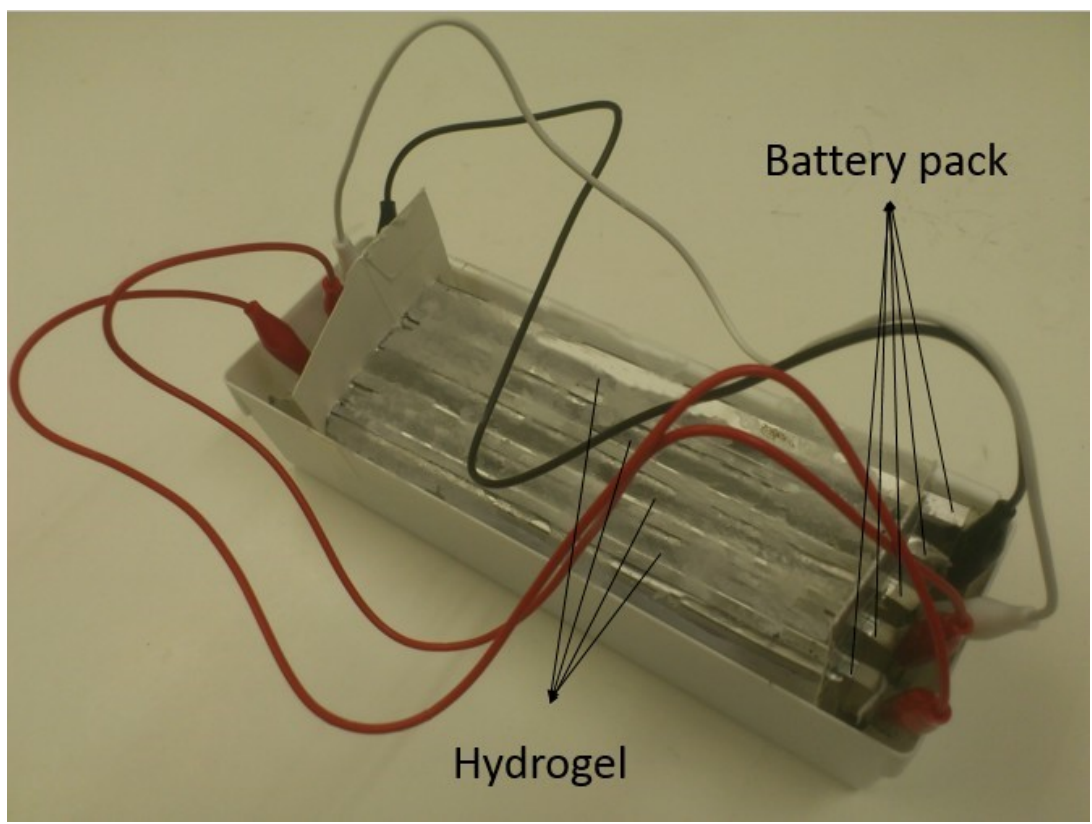

Figure 3.1 Hydrogel thermal management system on 8000 mAh battery pack. 
Before loading, both battery packs are charged at a specific C-rate with the voltage cut-off limits of $8.4 \mathrm{~V}$ and $21 \mathrm{~V}$ (4.2 $\mathrm{V}$ for each cell), respectively, followed by a potentiostatic mode until the current drops to $0.02 \mathrm{C}$. It takes $1 \mathrm{~h}$ for the battery cells to equilibrate, and then the discharge tests are carried out at different $\mathrm{C}$-rates until the voltage drops to $3 \mathrm{~V}$ per cell. In the discharge process, a thermistor is attached at the center of the battery pack (i.e., the position more susceptible to overheating) to measure the temperature variation. The initial temperature inside the test cardboard boxes is kept at $23^{\circ} \mathrm{C}$.

\subsubsection{Performance Evaluation of Hydrogel Thermal Management System in Short Term and Long Term}

After experimentally comparing the effects of different thermal management systems in cooling small and large Li-ion battery packs, a constant current discharge (CCD) experiment is then carried out with medium 4S1P 3 Ah battery pack, which follows the same charging scheme as described above. The initial temperature of the discharge process is between $22.5^{\circ} \mathrm{C}$ and $23.5^{\circ} \mathrm{C}$ and the cut-off voltage is set to $3 \mathrm{~V}$ for each cell. In the process, two thermocouples are attached on each battery pack to measure the temperatures. One thermal couple is placed in the center of the battery pack (point B in Fig. 3.2) and the other one is in the center of the battery surface (point A in Fig. 3.2). The dimensions and the components' properties of the $3 \mathrm{Ah}$ battery pack and its hydrogel BTM system are the same as those used in the thermal model that will be employed in the following simulation (Table 2 and 3). 

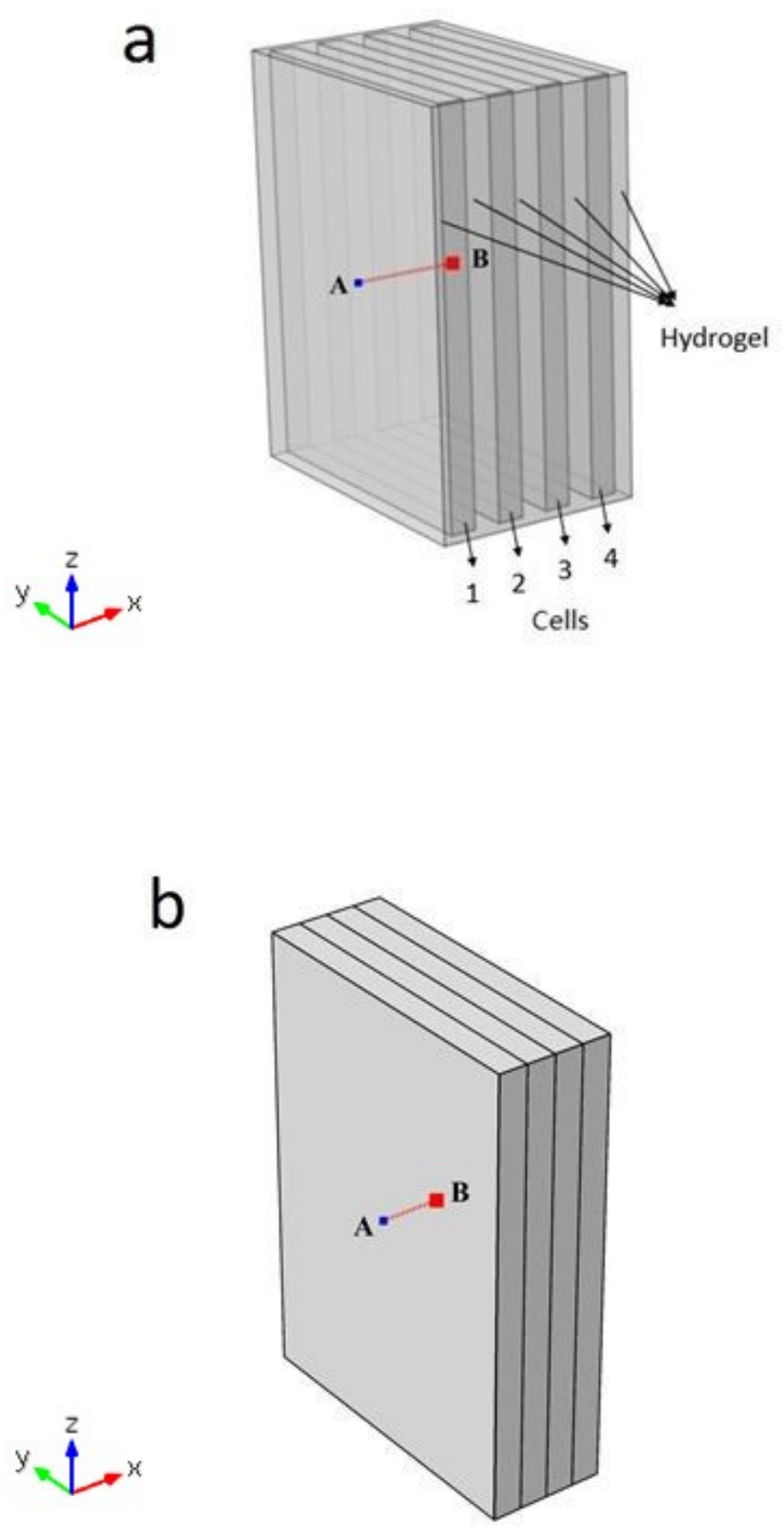

Figure 3.2 Schematic illustration of the models used in thermal simulations: (a) battery pack with hydrogel BTM system; and (b) battery pack without BTM system. 
Table 2. Specification of the cell components used in the simulation [23].

\begin{tabular}{llllll}
\hline Material/layer & Thickness & Number & Density & Heat & Thermal \\
& {$[\mu \mathrm{m}]$} & of layers & {$\left[\mathrm{kg} \mathrm{m}^{-3}\right]$} & capacity & conductivity \\
& & & & {$\left[\mathrm{J} \mathrm{kg}^{-1} \mathrm{~K}^{-1}\right]$} & {$\left[\mathrm{W} \mathrm{m}^{-1} \mathrm{~K}^{-1}\right]$} \\
\hline Negative electrode & 110 & 22 & 1347 & 1437 & 1.04 \\
Positive electrode & 71 & 22 & 2508 & 1269 & 1.58 \\
Aluminum foil & 21 & 12 & 2702 & 903 & 238 \\
Copper foil & 15 & 11 & 8930 & 385 & 398 \\
Separator & 20 & 24 & 1009 & 1978 & 0.334 \\
Pouch & 118 & 2 & 1150 & 1900 & 0.16 \\
\hline
\end{tabular}


Table 3. Cell specification and the properties of PAAS hydrogel.

Cell specification

Thickness

$5.17[\mathrm{~mm}]$

Width

$60[\mathrm{~mm}]$

Height

$84[\mathrm{~mm}]$

Weight

$63.8[\mathrm{~g}]$

Nominal voltage

$3.7[\mathrm{~V}]$

Nominal capacity

$3000[\mathrm{mAh}]$

Specific energy

177 [ $\mathrm{Wh} \mathrm{kg}^{-1}$ ]

Energy density

$386\left[\mathrm{Wh} \mathrm{L}^{-1}\right.$ ]

Operating temperature

$-20-60^{\circ} \mathrm{C}$

Hydrogel properties

Thickness between cells

$4[\mathrm{~mm}]$

Thickness at the outer sides of cell $1 \& 4$

$2[\mathrm{~mm}]$

Thermal conductivity

$0.605\left[\mathrm{~W} \mathrm{~m}^{-1} \mathrm{~K}^{-1}\right]$

Heat capacity

$4136\left[\mathrm{~J} \mathrm{~kg}^{-1} \mathrm{~K}^{-1}\right]$

Density

$964\left[\mathrm{~kg} \mathrm{~m}^{-3}\right]$

In the continuous 4-cycle high rate charge/discharge test on 4S 3Ah battery pack, no rest time is set either between the charge and discharge processes within one cycle or between two consecutive cycles. The discharge current and the maximum charge current are both set to be $7.5 \mathrm{~A}(2.5 \mathrm{C})$. A cut off temperature of $75^{\circ} \mathrm{C}$ is adopted in the test for safety consideration. As in the CCD test, the temperatures of two locations (pack center and surface center) are collected. 
During the capacity fade test on the 5S1P 8Ah battery, the battery pack is charged at $1 \mathrm{C}$ rate and then potentiostatically conditioned until the current decreases to $\mathrm{C} / 36$, which is closely followed by a discharge process at a constant current of $8 \mathrm{~A}$. No rest time is set between any two processes. The thickness of hydrogel between neighboring cells is 4.5 $\mathrm{mm}$, which is half the thickness of one cell, and no hydrogel is placed at the two outsides of the battery pack. The specifications of all the experimental tests are summarized in Table 4.

Table 4. Specification of experimental tests.

\begin{tabular}{lllll}
\hline & Test 1 & Test 2 & $\begin{array}{l}\text { Test } 3 \\
(4-c y c l e)\end{array}$ & $\begin{array}{l}\text { Test } 4 \\
\text { (fading test) }\end{array}$ \\
& $(\mathrm{CCD})$ & $(\mathrm{CCD})$ & $4 \mathrm{~S} 1 \mathrm{P}$ & $5 \mathrm{~S} 1 \mathrm{P}$ \\
\hline Configuration & $4 \mathrm{~S} 1 \mathrm{P}$ & $4 \mathrm{~S} 1 \mathrm{P}$ & $7.5 \mathrm{~A}(2.5 \mathrm{C})$ & $8 \mathrm{~A}(1 \mathrm{C})$ \\
Charge & $3 \mathrm{~A}(1 \mathrm{C})$ & $3 \mathrm{~A}(1 \mathrm{C})$ & 0 & 0 \\
Rest time & $1 \mathrm{~h}$ & $1 \mathrm{~h}$ & $7.5 \mathrm{~A}(2.5 \mathrm{C})$ & $8 \mathrm{~A}(1 \mathrm{C})$ \\
Discharge & $10 \mathrm{~A}$ & $3,5,7.5,10 \mathrm{~A}$ & 0 & 0 \\
Rest time & $1 \mathrm{~h}$ & $1 \mathrm{~h}$ & 4 & 300 \\
Cycles & 1 & 1 & Experiment & Experiment \\
Test method & Sim \& Exp & Experiment & & \\
\hline
\end{tabular}




\subsection{Thermal Model Setup}

The heat generated in a battery is comprised of two main parts: reversible heat and irreversible heat. The reversible heat is related to the entropy change during reaction, which can be written as [32]:

$Q_{r}=-\mathrm{I} T \frac{d U_{o c}}{d T}$

where I denotes the applied charge/discharge current, $T$ is the temperature of the battery, and $U_{o c}$ represents the open circuit voltage.

The other heat source $Q_{i}$ is related to the battery internal resistance (i.e., polarization resistance $R_{p}$ and internal contact resistance $\left.R_{I C}[33]\right)$ :

$Q_{i}=\mathrm{I}^{2}\left(R_{p}+R_{I C}\right)$

where I is the charge/discharge current.

The internal resistance usually contributes to most of the battery heating at high discharge rates [34, 35]. According to Chen et al. [36], the value of $d U_{o c} / d T$ in Eq. (3) is $0.00022 \mathrm{~V} \mathrm{~K}^{-1}$. After brief calculation with the given value, the heat generated from internal resistance is about 30 times compared to the heat generated due to reversible process at 10 A discharge rate. Therefore, in this work, only the heat generated by internal resistance is considered in modeling.

Fig. $3.2 \mathrm{a}$ and $3.2 \mathrm{~b}$ are the schematic diagrams of the pouch battery packs with/without (w/wo) hydrogel BTM system. The battery temperatures at point A (the left surface center 
of cell 1) and B (the right surface center of cell 2) in the figures are calculated in the model simulation, which correspond to the temperature record points in the experiments. The internal heat generation rate of the entire battery pack is calculated based on:

$Q_{i}=\mathrm{I}^{2}\left(\overline{R_{p}+R_{I C}}\right)=\mathrm{I}^{2} \bar{R}_{\iota}$

where $\bar{R}_{l}$ is the average internal resistance of the entire battery pack (cells connected in series) during the whole discharge process, which can be calculated by:

$\bar{R}_{\iota}=\sum_{i=1}^{n} \frac{R_{i}}{n}$

wherein, $R_{i}$ is the internal resistance of the battery pack at different depths of discharge and is shown in Fig. 3.3, which is measured by the battery analyzer (ESI PCBA 5010-4) in the discharge process, and $n$ is the data numbers. 


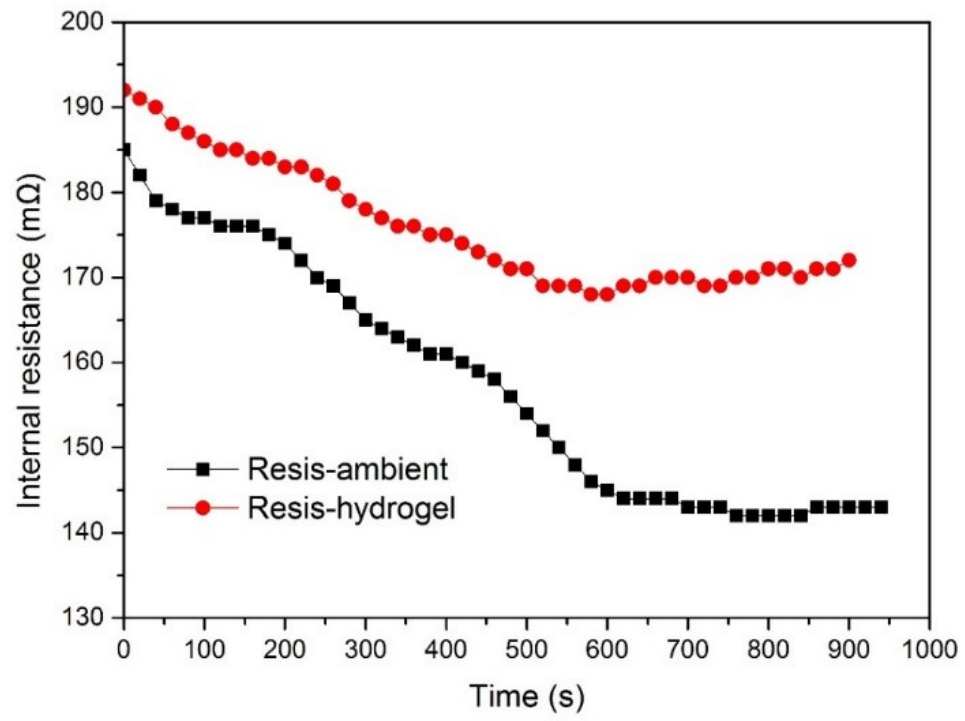

Figure 3.3 Internal resistance profile of $3 \mathrm{Ah}$ battery pack under $10 \mathrm{~A}$ discharge rate with and without hydrogel BTM system.

In the model, the thermal conductivity of the heat generation part in the $\mathrm{x}$ direction is calculated by [37]:

$$
k=\frac{\sum_{i=1}^{n} l_{i}}{\sum_{i=1}^{n} \frac{l_{i}}{k_{i}}}=1.04[\mathrm{~W} / \mathrm{m} \mathrm{K}]
$$

where $l_{i}$ and $k_{i}$ represent the thickness and heat conductivity of different components inside the cell. The following equation is the conductivity in $\mathrm{y}$ and $\mathrm{z}$ directions:

$$
k=\sum_{i=1}^{n} \frac{l_{i}}{l} k_{i}=26.1[\mathrm{~W} / \mathrm{m} \mathrm{K}]
$$


The density and specific heat capacity $\rho c_{p}$ is calculated based on the thickness of each component:

$$
\rho c_{p}=\sum_{i=1}^{n} \frac{\rho_{i} c_{p, i} l_{i}}{l}=2421\left[\mathrm{~kJ} / \mathrm{m}^{3} \mathrm{~K}\right]
$$

The simulation parameters of the cell components are listed in Table 2.

In a battery cell, the transient 3-dimensional energy balance equation is:

$\rho c_{p} \frac{\partial T}{\partial t}=\nabla \cdot(k \nabla T)+Q$

where the $Q$ is the heat source part calculated from equation (5). At the surface boundary of the battery pack without BTM system, convection part $q_{c}$ and radiation part $q_{r}$ are considered:

$$
\begin{aligned}
& q_{c}=h_{c}\left(T-T_{a m b}\right), \\
& q_{r}=\varepsilon_{e} \sigma\left(T^{4}-T_{a m b}{ }^{4}\right)
\end{aligned}
$$

Eqs. (11) and (12) can be further combined as:

$$
k \frac{\partial T}{\partial l}=h_{c}\left(T_{a m b}-T\right)+\varepsilon_{e} \sigma\left(T_{a m b}{ }^{4}-T^{4}\right)
$$


where $h_{c}, T_{a m b}, T, \varepsilon_{e}$ and $\sigma$ denote the convective heat transfer coefficient (set at $5 \mathrm{~W} \mathrm{~m}^{-2}$ $\mathrm{K}^{-1}$ ), ambient temperature, battery surface temperature, emissivity and Stefan-Boltzmann constant.

In the battery pack with hydrogel BTM system implemented, the energy balance equation of the cell is the same as that without BTM system based on equation (10). As for the hydrogel block, the energy balance equation is:

$\rho_{h} c_{p_{h}} \frac{\partial T_{h}}{\partial t}=\nabla \cdot\left(k_{h} \nabla T_{h}\right)$

where the subscript $h$ represents the hydrogel BTM system. In the model with hydrogel, the boundary conditions between cell and hydrogel, hydrogel and air interface, cell and air are given by:

$k \frac{\partial T}{\partial l}=k_{h} \frac{\partial T_{h}}{\partial l}$,

$-k_{h} \frac{\partial T_{h}}{\partial l}=h_{c}\left(T_{h}-T_{a m b}\right)$

and

$-k \frac{\partial T}{\partial l}=h_{c}\left(T-T_{a m b}\right)$

The cell specification and hydrogel properties used in simulation are summarized in Table 3.

In simulation, the total heat generation time is set to $1080 \mathrm{~s}$, which is the expected 
discharge time for a 3 Ah battery at 10 A discharge rate, and the emissivity used in the model is 0.3 [38]. Totally 606,000 and 425,000 elements are meshed with the minimum element quality of 2.53E-7 and 7.98E-5 for battery packs w/wo hydrogel BTM system, respectively. The element size is dependent on the complexity of pack components and the related governing equations.

\subsection{Results and Discussion}

\subsubsection{Comparison of Thermal Management Systems}

The heat dissipation capacities of these four BTM systems were evaluated by comparing: a) the temperature rises of the $1300 \mathrm{mAh} \mathrm{Li-ion} \mathrm{battery} \mathrm{packs} \mathrm{at} \mathrm{three} \mathrm{discharge}$ rates (i.e., 1C, $2 \mathrm{C}$, and $4 \mathrm{C}$ ); and b) the temperature rises of the $8000 \mathrm{mAh}$ battery pack at the discharge rate of $1 \mathrm{C}$. The testing results are summarized in Table 5 and in the meantime Figs. 3.4 and 3.5 respectively show the detailed temperature vs. time profiles of the 1300 $\mathrm{mAh}$ and $8000 \mathrm{mAh}$ battery packs with four battery thermal management strategies during the discharge processes, from which the following observations can be made: 1) the PAAS hydrogel performs similarly as the cooling fan does when dealing with low-capacity battery packs at low discharge rates (e.g., 1C and 2C); 2) both the PAAS hydrogel and the cooling fan perform much better than the other two BTM systems in suppressing the temperature rises when dealing with low-capacity battery pack at low discharge rates; and 3) the PAAS hydrogel demonstrates its superiority over the other three BTM systems in controlling the temperature rises when dealing with high-capacity battery packs or when dealing with lowcapacity battery packs but at high discharge rates (e.g., 4C). 

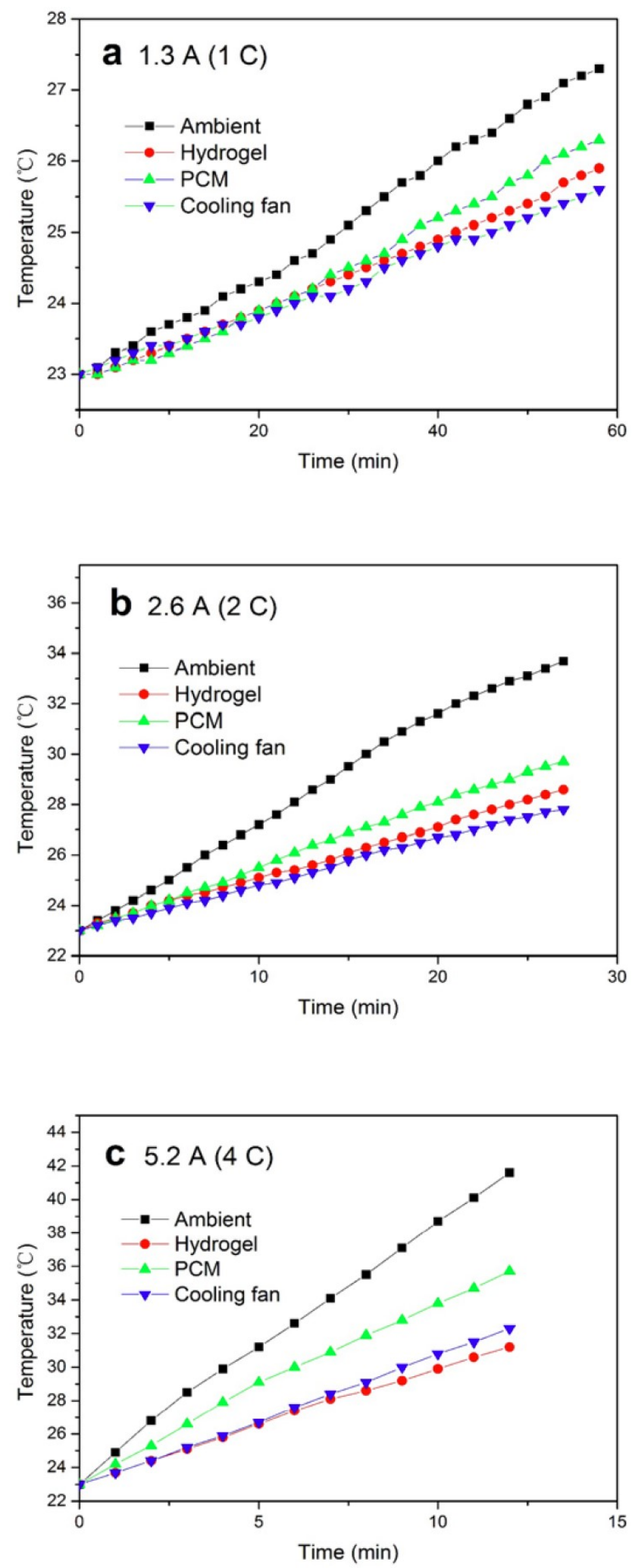

Figure 3.4 Temperature vs. time profiles of $1300 \mathrm{mAh}$ battery pack with four BTM strategies in the discharge processes at discharge rates of (a) $1 \mathrm{C}$, (b) $2 \mathrm{C}$, and (c) $4 \mathrm{C}$. 


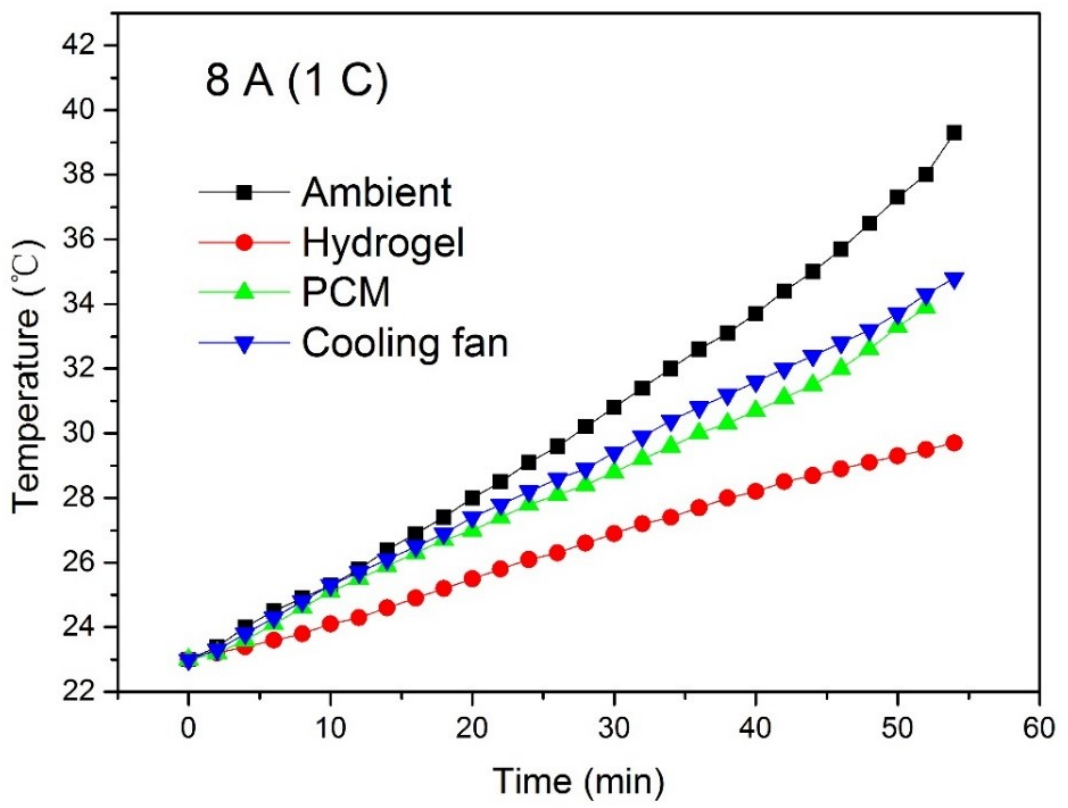

Figure 3.5 Temperature vs. time profile of $8000 \mathrm{mAh}$ battery pack with four BTM strategies in the discharge processes at a discharge rate of $1 \mathrm{C}$.

Table 5. Summary of the temperature rises at the center of battery modules during the discharge cycle at various C-rates in different BTM systems.

\begin{tabular}{lllll}
\hline $\begin{array}{l}\text { Discharge } \\
\text { current }\end{array}$ & $\begin{array}{l}\text { Ambient } \\
\left({ }^{\circ} \mathrm{C}\right)\end{array}$ & $\begin{array}{l}\text { Cooling fan } \\
\left({ }^{\circ} \mathrm{C}\right)\end{array}$ & $\begin{array}{l}\text { Traditional PCM } \\
\left({ }^{\circ} \mathrm{C}\right)\end{array}$ & $\begin{array}{l}\text { PAAS Hydrogel } \\
\left({ }^{\circ} \mathrm{C}\right)\end{array}$ \\
\hline $1.3 \mathrm{~A}(1 \mathrm{C})^{\mathrm{a}}$ & 4.3 & 2.7 & 3.3 & 2.9 \\
$2.6 \mathrm{~A}(2 \mathrm{C})^{\mathrm{a}}$ & 10.7 & 4.8 & 6.7 & 7.6 \\
$5.2 \mathrm{~A}(4 \mathrm{C})^{\mathrm{a}}$ & 16.7 & 8.6 & 11.5 & 6.7 \\
$8 \mathrm{~A}(1 \mathrm{C})^{\mathrm{b}}$ & 16.3 & 11.8 & 10.9 & \\
\hline a: $1300 \mathrm{mAh}$ battery pack & & &
\end{tabular}


After validating the effectiveness of the hydrogel cooling system in controlling the temperature rise during discharge, the feasibility of implementing it in real applications needs to be verified. Generally, a qualified passive BTM system requires the cooling material filled inside remains stable over the whole temperature range of battery usage. Since water is known to be evaporating and changing volume during phase change (from liquid to solid at low temperatures), the consequent mass decrease and volume change of hydrogel and the relevant safety issues caused by moisture deserve further investigation. First, an evaporation test has been carried out by placing two $25 \mathrm{ml}$ graduated cylinders, filled with water and hydrogel, respectively, in the environmental chamber at $80^{\circ} \mathrm{C}$ for 12 $\mathrm{h}$, and the testing results show that the average evaporation rates for water and hydrogel are 0.46 and $0.38 \mathrm{~g} \mathrm{~h}^{-1}$, respectively, under this testing condition. The relatively lower evaporation rate for hydrogel is attributed to the hydrogen bonds between PAAS and water, and it requires more energy for the water to vaporize out from the networks. If the temperature of battery reaches $100^{\circ} \mathrm{C}$ (though not usually happen during the normal operation of Li-ion battery), the water will vaporize to maintain the temperature of the battery pack at this temperature and does not go higher. To better address this water evaporation issue, the methods based on an open structure and a closed structure are proposed for future applications. In an open structure, the hydrogel system wrapped around the battery pack is designed with a refilling inlet and a venting outlet. The inlet facilities the BTM system to be refilled with water periodically while the outlet allows the vapor to be evaporated directly to the ambient, thereby hindering the rise of humidity around the battery tabs and alleviating the relevant safety concerns. In practice, the application of the open structure needs to take into consideration several important factors such as the 
hydrogel amount monitoring, the opening size, and the refilling frequency. The complexity involved in designing such an open structure makes it more suitable for the large and stationary battery systems, where a fully automated online supervision system can be implemented. As for the small-scale and/or mobile applications, a closed structure rather than an open one is more preferred. As the name implies, in a closed structure, the battery package with hydrogel BTM system is completely sealed with only the battery tabs left outside. Since the saturated pressure of water is as low as $47.39 \mathrm{kPa}$, which is less than half the atmosphere pressure, even at $80^{\circ} \mathrm{C}$ (when the vapor and water coexist) [39], the sealed battery pack is safe and stable at high temperatures and there would be no mass loss and humidity increase. Second, the volume changes of water and PAAS hydrogel are further investigated. Although the water expands (by approximately $8.3 \%$ ) from liquid state to solid state, the volume change of hydrogel during phase change is much smaller (only $3.47 \%)$. This is due to the already-experienced expansion of hydrogel during gelatinization. Also, the density of hydrogel at room temperature $\left(23^{\circ} \mathrm{C}\right)$, around $950 \mathrm{~kg} \mathrm{~m}^{-3}$, is close to the lowest ice density $\left(\right.$ at $\left.0^{\circ} \mathrm{C}\right), 917 \mathrm{~kg} \mathrm{~m}^{-3}$. The small volume expansion caused by the difference in density can be readily resolved by leaving a small void space inside the pack. This approach has been successfully applied to the PCM-based (phase change expansion of $15 \%)$ BTM system [40, 41]. Also, to avoid expansion, a certain amount of ethylene glycol can be added to water prior to the gel reaction, considering the low temperature level. In [16], a temperature bath based on this mixture has been applied to control the battery temperature, and the mixture has been proved to be functioning at $-20^{\circ} \mathrm{C}$ in liquid state. A recent low temperature test also shows that the PAAS hydrogel mixed with 35 wt.\% ethylene glycol is ice-free down to $-20^{\circ} \mathrm{C}$. It should be noted that in extremely cold 
conditions a heating system rather than a cooling one may be used.

\subsubsection{PAAS Hydrogel vs. Active Air-Cooling}

Both the PAAS hydrogel and the air-cooling method prove to be very effective in controlling the temperature rises of the battery packs during the low current discharge processes. For the 1300 mAh battery packs, the air-cooling BTM system performs better but consumes a certain amount of power that cannot be neglected. For example, the power consumed by the cooling fan in $1 \mathrm{C}$ discharge process of the $1300 \mathrm{mAh}$ battery pack accounts for as much as $30 \%$ of the total energy of the pack. This would impose challenges to portable battery packs in real-world applications. At high current discharge tests, although the percentage of the power consumed by fan is reduced, the performance of cooling fan BTM system shows to be less effective than the hydrogel system (Figs. 3.4c and 3.5). This is because more heat is generated when the current increases based on Eq. (5), however, the heat dissipation rate of cooling fan remains unchanged. By contrast, the hydrogel-based BTM system has a passive cooling mechanism, and the quantity of hydrogel is varied with the size of the cell without compromising the compactness of the whole battery pack, which ensures its effectiveness in controlling the thermal surge when dealing with various battery packs.

\subsubsection{PAAS Hydrogel vs. Traditional PCM}

The PAAS hydrogel and traditional PCMs are used as passive cooling methods in the discharge tests and their thermal properties are listed in Table 6. The specific heat capacity and heat conductivity of the hydrogel are determined by equations (1) and (2). In all the 
discharge tests, the proposed PAAS hydrogel outperforms the PCM in controlling the temperature rises, and the superiority of the PAAS hydrogel over the PCM becomes more evident when dealing with higher capacity battery packs or discharging at high rates. This is because: 1) from the specific heat capacity perspective, the PCM can generally absorb a great amount of heat without a marked temperature change in the phase change process. However, this phase change process usually takes place at a relatively high temperature range $\left(42-45^{\circ} \mathrm{C}\right.$ in this case), which may already adversely affected the health of the battery packs (it is reported that the life span of Li-ion batteries can be reduced by about two months for every degree of temperature rise in an operating range of $30-40^{\circ} \mathrm{C}$ [42]). The ideal operational temperature range for $\mathrm{Li}$-ion batteries is usually around $30^{\circ} \mathrm{C}$ that is still under the melting points of most PCMs, where the sensible heat rather than the latent heat is the major source of the absorbed heat. Given that the PAAS hydrogel typically possesses twice the specific heat capacity of the PCMs, the hydrogel based BTM system can perform much better than the PCMs in suppressing the battery pack temperature rises within this temperature range. 2) From the heat conductivity perspective, the heat conductivity of the PAAS hydrogel is approximately $0.61 \mathrm{~W} \mathrm{~m}^{-1} \mathrm{~K}^{-1}$ at $25^{\circ} \mathrm{C}$, much higher than that of most PCMs (approximately $0.25 \mathrm{~W} \mathrm{~m}^{-1} \mathrm{~K}^{-1}$ at $25^{\circ} \mathrm{C}$ ), and their heat conductivities increase almost linearly as the temperature rises. Owing to its higher heat conductivity, the hydrogel based BTM system is capable of distributing the heat in a more efficient manner, especially when dealing with high-capacity battery pack discharge or discharge at high rates. 
Table 6. Thermal properties of PAAS hydrogel and PCM used as battery thermal management materials in the discharge tests.

\begin{tabular}{lll}
\hline Thermal property & PCM & PAAS hydrogel \\
\hline Specific heat capacity $\left(\mathrm{kJ} \mathrm{kg}^{-1} \mathrm{~K}^{-1}\right)$ & 2.14 & 4.14 \\
Thermal conductivity $\left(\mathrm{W} \mathrm{m}^{-1} \mathrm{~K}^{-1}\right)$ & 0.25 (solid) & 0.61 \\
& 0.19 (liquid) & \\
Melting range $\left({ }^{\circ} \mathrm{C}\right)$ & $42-45$ & - \\
\hline
\end{tabular}

\subsubsection{Hydrogel BTM system in High Rate CCD Test: Comparison of Experiment and Simulation}

The internal resistances of the 4S 3 Ah battery pack at $10 \mathrm{~A}$ discharge rate, both with and without hydrogel BTM system, are measured by the battery analyzer at different depths of discharge, and the results are shown in Fig. 3.3. The average internal resistance of the battery pack is calculated by Eq. (6) in which the resistance data are from the measurement of battery analyzer during the experiment, and the corresponding average heat generation rates calculated from Eq. (5) are $17.6 \mathrm{~W}$ and $15.6 \mathrm{~W}$ with and without hydrogel BTM system, respectively, which are used in the simulation as the input power. The relatively lower resistance in ambient condition is due to the enhancement in the mobility of electrons and improvement in the diffusion coefficient of the ions at high temperature.

The effectiveness of hydrogel BTM system on thermal control is validated by the temperature responses of 3 Ah battery pack with and without hydrogel during discharge. The thickness of hydrogel layer is $4 \mathrm{~mm}$, which is relatively thinner than the cell in battery pack (Table 3). Fig. 3.6 depicts the temperature change and distribution in battery pack. 
Although a slight difference in temperature is observed between simulation and experimental results, which may probably because the reversible heat is neglected and uneven heat distribution in battery cells, the overall trend and final results of simulation agree well with the experimental results. The overall temperature of the battery pack remains at a low level when the hydrogel BTM system is implemented (Fig. 3.6b), while high temperatures are observed when no BTM system is implemented (Fig. 3.6a). Without BTM system, the temperatures in the center of battery pack after discharge process reach $71.4^{\circ} \mathrm{C}$ and $76.8^{\circ} \mathrm{C}$ for simulation and experimental results, respectively; at the surface center of battery pack, the final temperatures in simulation and experiment are $65.4^{\circ} \mathrm{C}$ and $66.2^{\circ} \mathrm{C}$, respectively. The results from both the simulation and experiment have shown that the temperatures at battery pack surface or center are high enough to cause safety concern at 10 A discharge test when no BTM system is implemented, considering the safety operation temperature range of the battery is $-20^{\circ} \mathrm{C}-60^{\circ} \mathrm{C}$. When hydrogel $\mathrm{BTM}$ system is implemented in the pack, the dramatic temperature drop compared to that in ambient condition can be seen from both simulation and experimental results. The highest temperature after discharge in battery pack is below $50^{\circ} \mathrm{C}$, which is in the safety operation temperature range of $\mathrm{Li}$-ion batteries. 

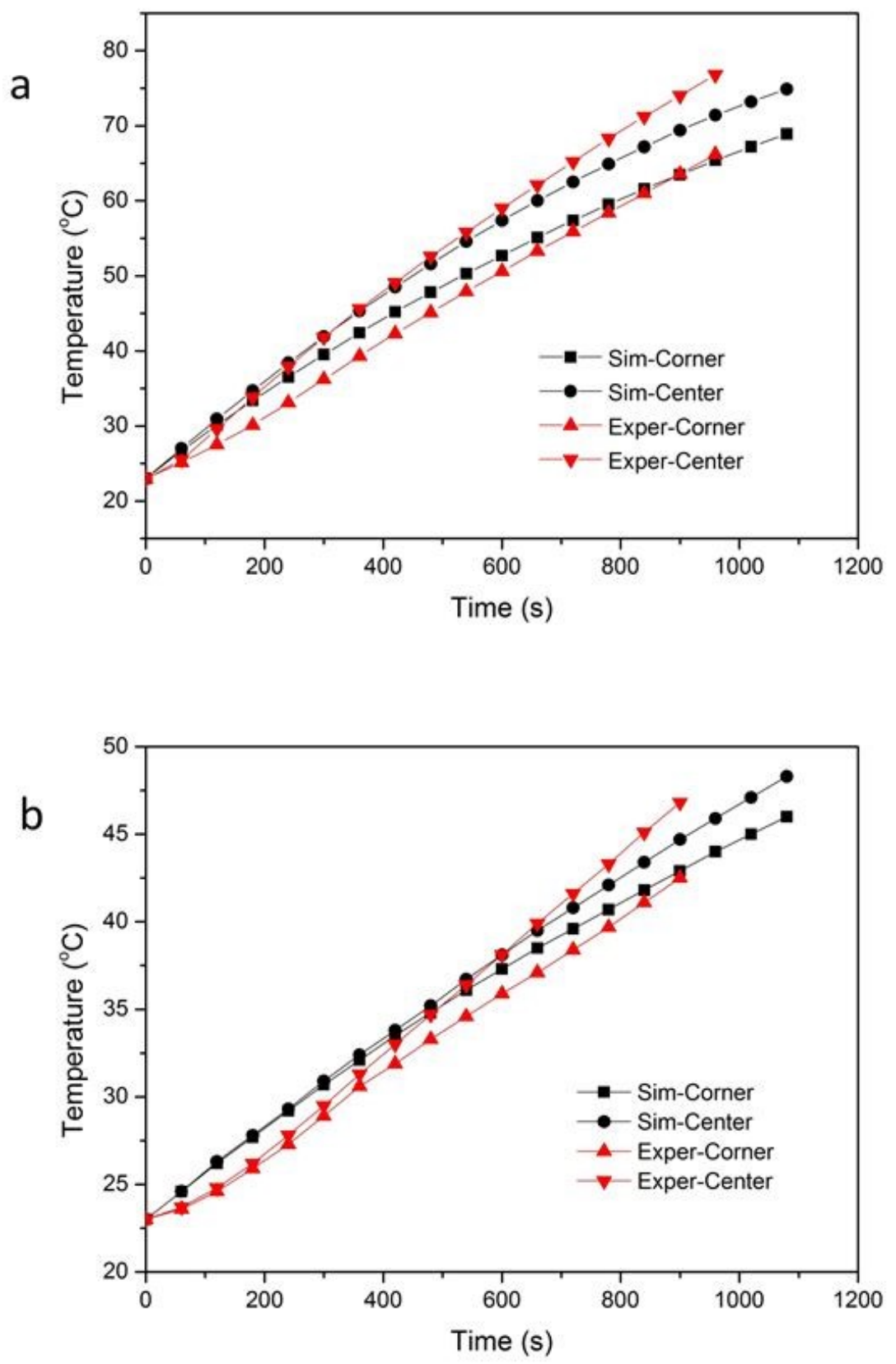

Figure 3.6 Temperature profiles for the $3 \mathrm{Ah}$ battery pack at $10 \mathrm{~A}$ discharge current in both simulation and experiment, (a) without BTM system, (b) with hydrogel BTM system implemented.

Another point that is worthy to note is the temperature uniformity inside the battery pack. When the battery is discharged in ambient condition, the temperature difference between points $\mathrm{A}$ and $\mathrm{B}$ is $10.6^{\circ} \mathrm{C}$ (in experiment) and decreases to $4.3^{\circ} \mathrm{C}$ when the 
hydrogel BTM system is implemented. Park pointed out that it is desirable to have a uniform temperature distribution in a single cell or module [43]. Kizilel mentioned that the cell in battery pack will undergo different fading rates due to the different surrounding temperatures and eventually result in faster fading rate and lower capacity utilization [29]. The temperature difference in the simulation results of the battery pack w/wo hydrogel BTM system, as seen in Fig. 3.7, is smaller than that in the experiment. This is because the battery model in simulation is assumed to dissipate heat equally in all directions of the pack (cells are generating the same amount of heat at the same rate), which may actually be variable in real experiments. Nevertheless, the temperature difference for the battery pack under ambient condition is more than twice of that with hydrogel BTM system in simulation. 


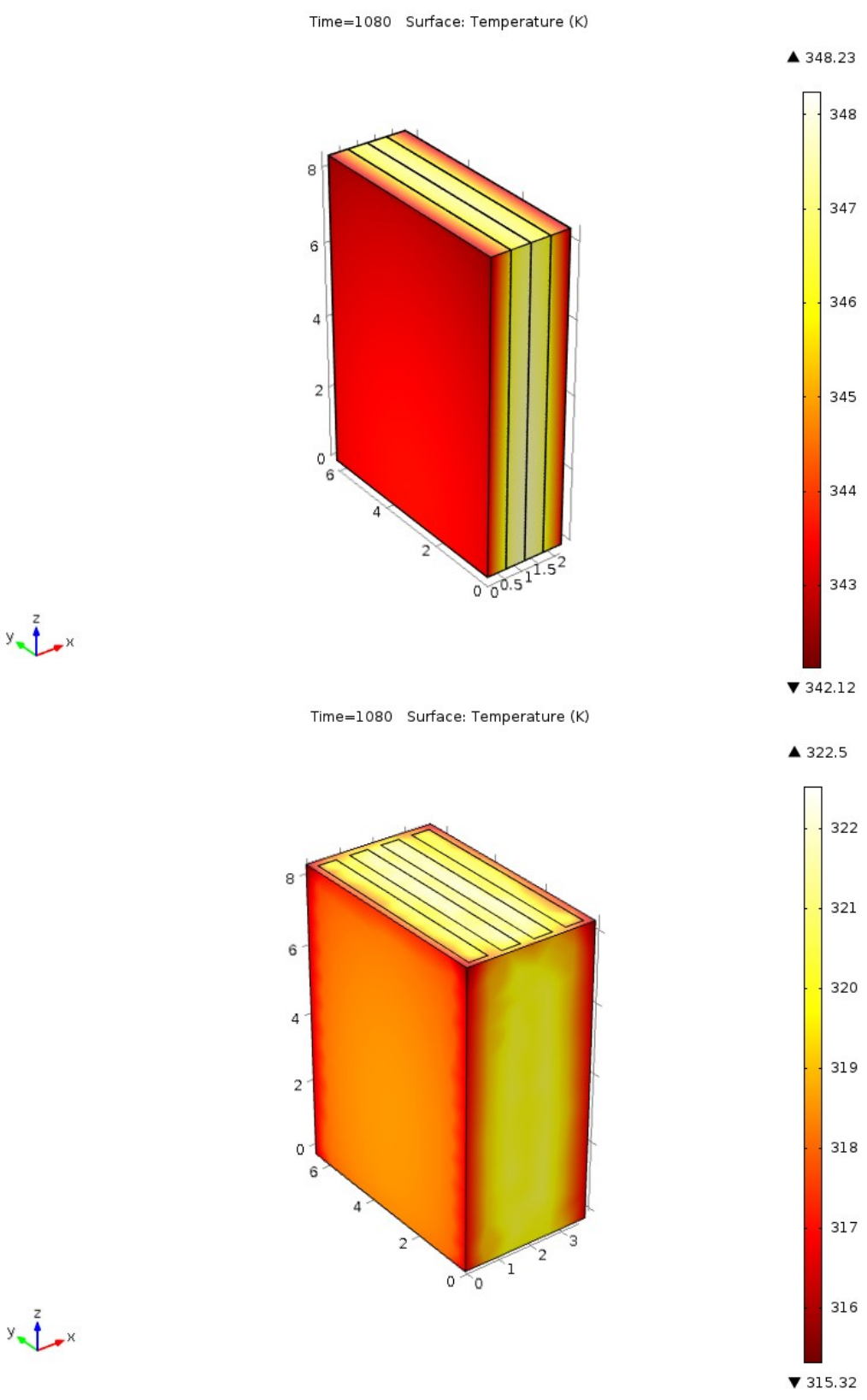

Figure 3.7 Numerical simulation profiles of temperature distribution inside battery pack w/wo hydrogel BTM system at the end of discharge.

\subsubsection{Effect of Hydrogel BTM system in CCD Tests at Various Discharge Rates}

The 4S1P 3 Ah battery pack is tested at four discharge rates in both ambient condition and hydrogel BTM system. The space between the cells in battery pack still remains at 4 
$\mathrm{mm}$ when hydrogel is implemented. Fig. 3.8 compares the variations in temperature at two assigned locations (points A and B) of the battery pack at four discharge currents: $3 \mathrm{~A}, 5$ $\mathrm{A}, 7.5 \mathrm{~A}$ and $10 \mathrm{~A}$. It is clear that the temperature increase rate and the final temperature value in ambient condition are much greater than those in hydrogel. As is stated earlier, the life span of Li-ion batteries can be reduced by about two months for every degree of temperature rise in an operating range of $30-40^{\circ} \mathrm{C}$ [42], which demonstrates the significant influence of temperature on Li-ion batteries. In the experimental tests, the temperature of the battery pack without hydrogel BTM system always keeps at a high level, even at $1 \mathrm{C}$ discharge rate, $3 \mathrm{~A}$. The center temperature reaches $45^{\circ} \mathrm{C}$ at the end of discharge, which is higher than the suggested operating temperature range, and the temperature can even reach $77^{\circ} \mathrm{C}$ when operating at $10 \mathrm{~A}$. When the hydrogel BTM system is employed, the center temperature of the battery pack experiences mild increase at every selected current level. The highest temperatures of point $\mathrm{B}$ (in the center of the battery pack) are below $35^{\circ} \mathrm{C}$ when the discharge rates are $3 \mathrm{~A}$ and $5 \mathrm{~A}$. Even in stressed condition, with the discharge rate as high as 7.5 and $10 \mathrm{~A}$, the highest temperature is around $45^{\circ} \mathrm{C}$, which is unlikely to induce poor performance, overheating or thermal runaway. 

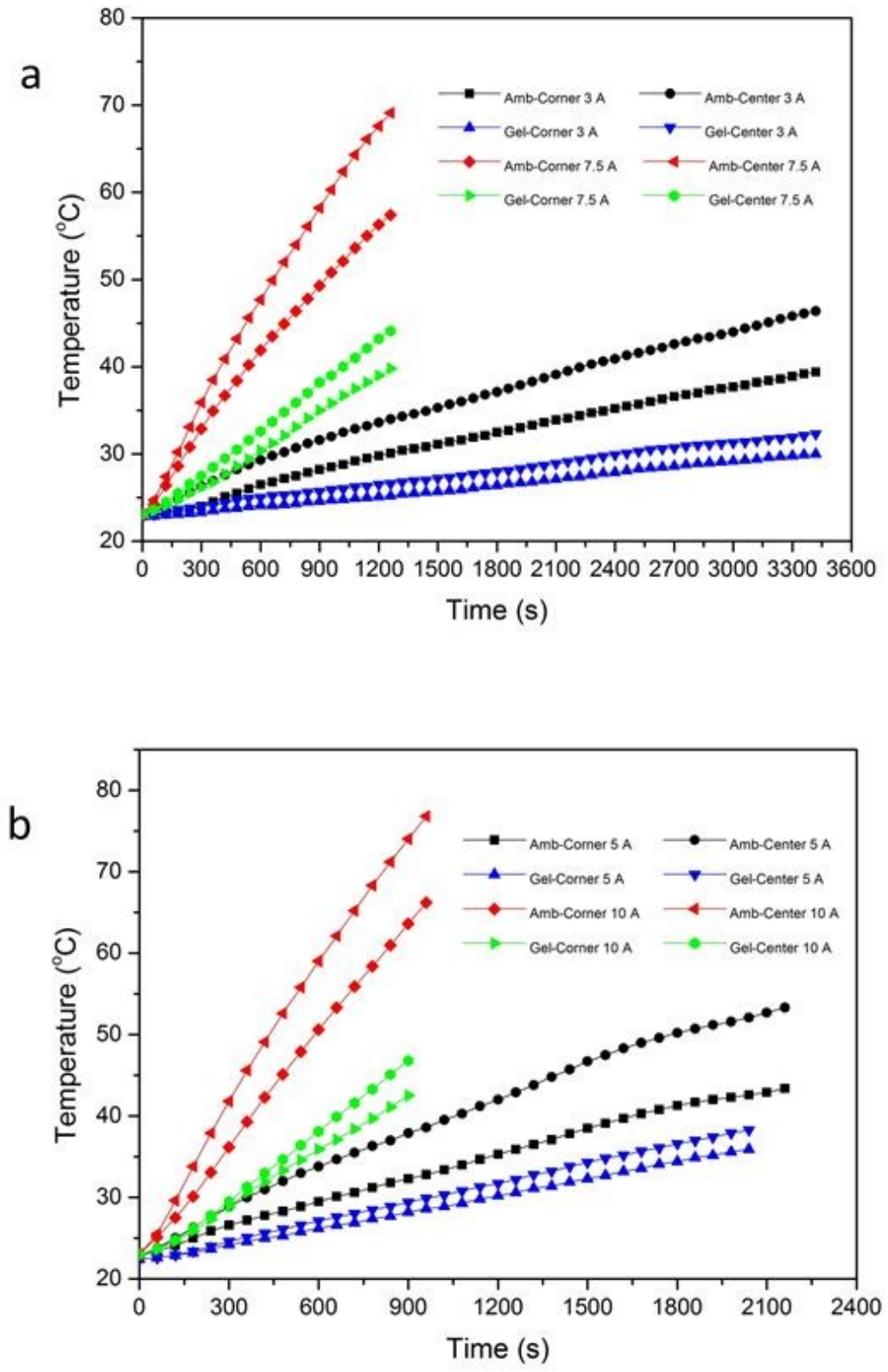

Figure 3.8 Thermal response of the packs w/wo hydrogel BTM system at different discharge currents:

(a) $3 \mathrm{~A}, 7.5 \mathrm{~A}$, and (b) $5 \mathrm{~A}, 10 \mathrm{~A}$.

The temperature differences between the specified points $\mathrm{A}$ and $\mathrm{B}$ for different discharge currents in two battery packs are shown in Fig. 3.9. It is clear to see that the 
temperature difference generally increases with the increase of discharge current, but is obviously smaller when the hydrogel BTM system is implemented in the battery pack. For example, the temperature difference of the pack in hydrogel BTM system at a discharge rate of $7.5 \mathrm{~A}$ is only $4.5^{\circ} \mathrm{C}$ at the end of discharge process, which is much smaller than the $11.8^{\circ} \mathrm{C}$ for that in ambient condition. Even at a lower discharge rate, the temperature difference of the ambient pack can be as high as $7^{\circ} \mathrm{C}$, which will consequently increase the fading rate of the battery pack. More than just convective cooling, the hydrogel BTM system also has a conductive cooling mechanism, which makes it more effective than the pure natural convection and radiation heat dissipation pattern. Meanwhile, the hydrogel BTM system blocked in the battery pack is united, so the uneven heat generated in the battery can be dissipated by the localized hydrogel and distribute evenly throughout the whole battery pack. Therefore, a uniform temperature distribution can be achieved, which will assure a good performance of the battery pack. 

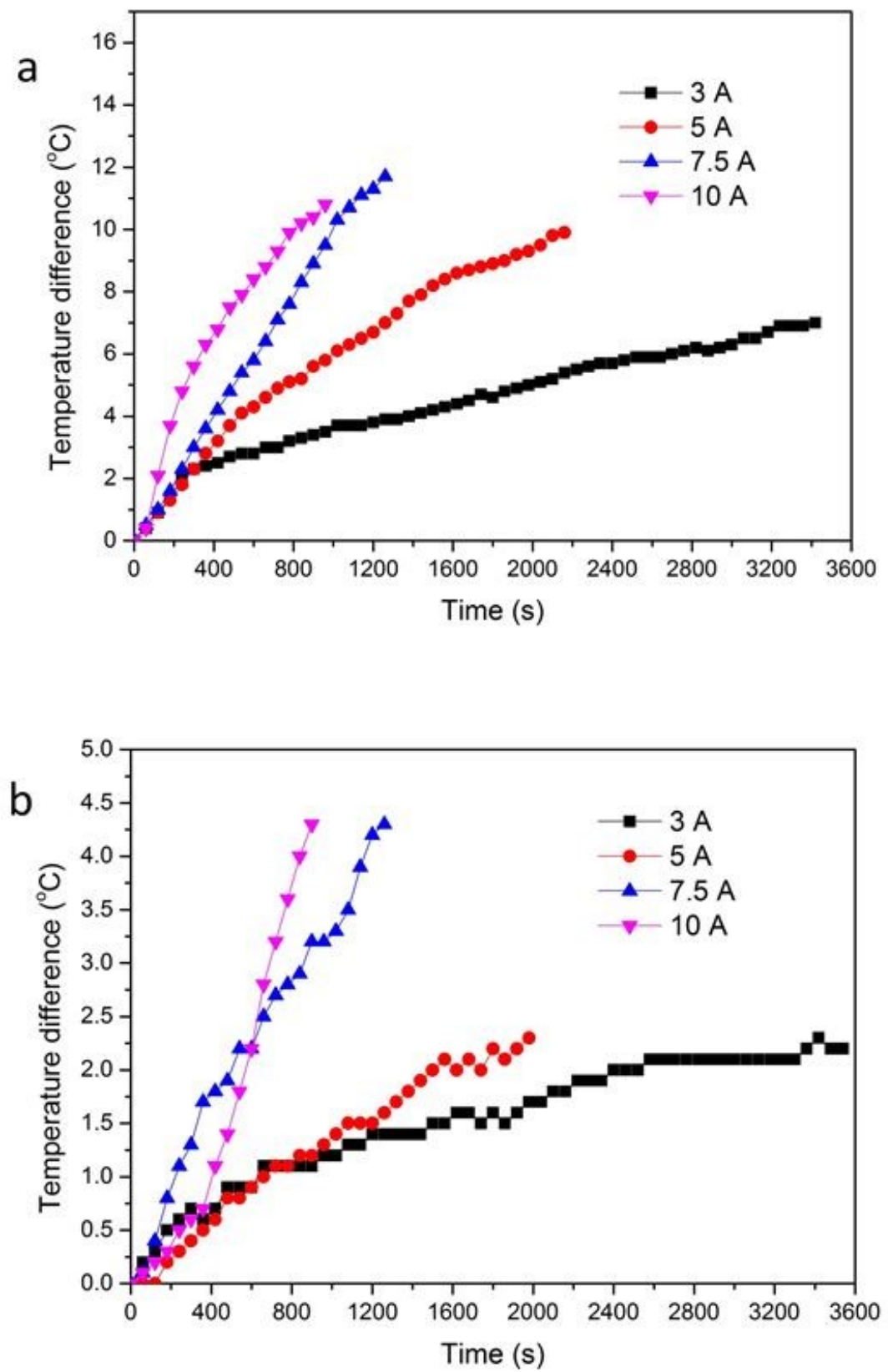

Figure 3.9 Temperature differences of two assigned points in the battery pack under different discharge rates (a) without BTM system and (b) with hydrogel BTM system.

\subsubsection{Hydrogel BTM system in Continuous Cyclic Safety Test}

A 4-cycle 7.5 A continuously charge and discharge test is performed on the battery 
pack w/wo hydrogel BTM system, in which the temperatures at the specified points are measured. For safety concern, during the test, the temperature limit is set to $75^{\circ} \mathrm{C}$. In Fig. 3.10, the black squares represent the current, where the positive current means the discharge process and negative current indicates the charge process. The charging is ended following a potentiostatic stage until the current drops to $\mathrm{C} / 36$. 

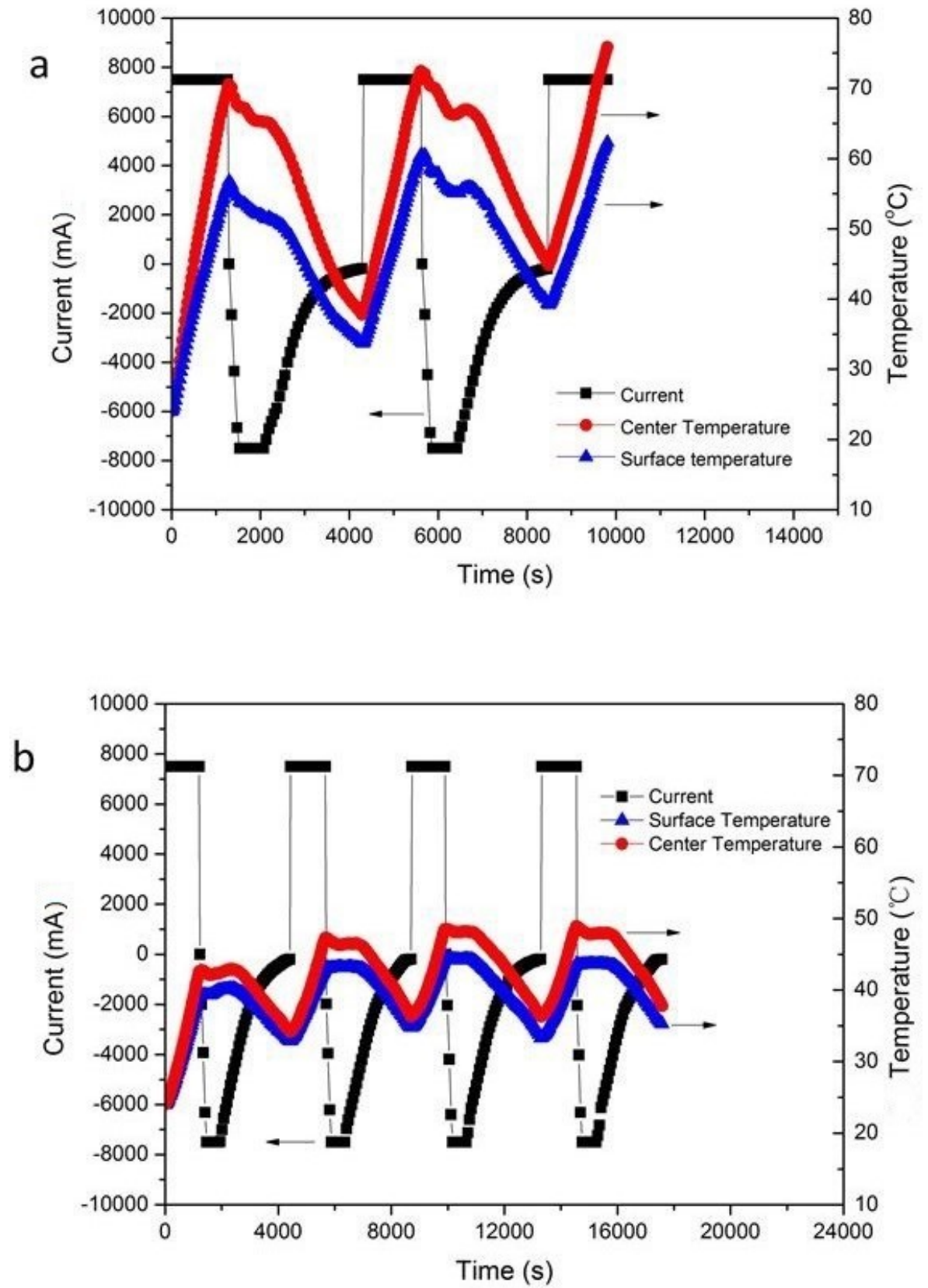

Figure 3.10 Four-cycle safety test of the battery pack under $7.5 \mathrm{~A}$ continuous charge and discharge process: (a) in ambient condition, (b) with hydrogel BTM system.

As seen from Fig. 3.10a, the temperature at the pack center reaches $70^{\circ} \mathrm{C}$ after the first discharge process. Although the temperature decreases in the subsequent charge process, the final temperature is still higher than the initial temperature before discharging. During 
the second cycle, the temperature at the end of discharge $\left(73^{\circ} \mathrm{C}\right)$ almost reaches the temperature limit. Due to the equilibrium of the generated heat and dissipated heat at the early stage of charging, there is a relatively stable region in the temperature profile, which is followed by a rapid decline stage as a result of the decrease of charge current. At the end of the third discharge process, the cycle test is forced to stop as the temperature reaches the preset limit $\left(75^{\circ} \mathrm{C}\right)$. The test is carried out at $23^{\circ} \mathrm{C}$, however, in reality, for example in summer, with an initial temperature higher than $35^{\circ} \mathrm{C}$, the battery operated without hydrogel BTM system will have the potential to lead to thermal runaway in the first discharge process. As a comparison, the battery pack tested with hydrogel BTM system (shown in Fig. 3.10b) completes the entire four cycles with the highest temperature of only $48^{\circ} \mathrm{C}$, and the biggest temperature difference at the two selected points is $5.3^{\circ} \mathrm{C}$, which is much lower when compared to the $14^{\circ} \mathrm{C}$ in ambient condition. Meanwhile, at the end of the $2 \mathrm{nd}, 3 \mathrm{rd}$ and 4 th charge process, the temperature drops back close to the previous initial discharge temperature, which indicates that the battery with hydrogel BTM system can stabilize its operation within a safe temperature range.

\subsubsection{Hydrogel BTM system in Capacity Fading Test}

The capacity fading rate of batteries is another important indicator to the effectiveness of a BTM system in the long term operation. Two newly built 5S1P battery packs with 8 Ah nominal capacity for each cell are used in the test. One of them is implemented with the hydrogel BTM system, and the space between the neighboring cells is kept at half the thickness of the cell $(4.5 \mathrm{~mm})$; the other battery is packed without BTM system. In the test, charge and discharge are preformed alternately without rest time, which provides a stressed 
condition for the battery packs. The ambient temperature is kept at $30^{\circ} \mathrm{C}$ in an environment chamber for a faster fading rate of the tested batteries. Fig. 3.11 shows the voltage curves of the battery packs in ambient condition and in hydrogel BTM system during the 2nd discharge process, which has the highest discharge capacity among all the cycles (the solid electrolyte interphase (SEI) layer is formed in the first cycle). In the whole process, the voltage of the battery pack in ambient condition is slightly higher than that in hydrogel BTM system at same time point, and the battery in ambient lasts longer during discharge. As mentioned in Ref. [44], the higher discharged capacity (discharge more completely) can generally be achieved at a higher temperature within the safety temperature range, which is due to a higher electrolyte conductivity and better electrode wetting characteristic of the battery. As proved in Fig. 3.12, at the end of the 2nd discharge process, the center temperature of the battery packs reach $47.3^{\circ} \mathrm{C}$ and $37.5^{\circ} \mathrm{C}$ in ambient and in hydrogel, respectively, corresponding to the measured discharged capacities, $8001 \mathrm{mAh}$ and 7977 mAh, of the two packs. However, although more capacity can be released in the initial discharge cycles, a high temperature has many adverse effects on the long term performance of battery, such as inducing the change of the composition and morphology of the SEI [45], causing the exothermic side reactions and even self-heating of the lithiated carbon electrode [46, 47]. Amine et al. illustrated in Ref. [48] that between the room temperature $\left(25^{\circ} \mathrm{C}\right)$ and $55^{\circ} \mathrm{C}$, the increase of temperature will exacerbate the capacity fading of the Li-ion battery. 


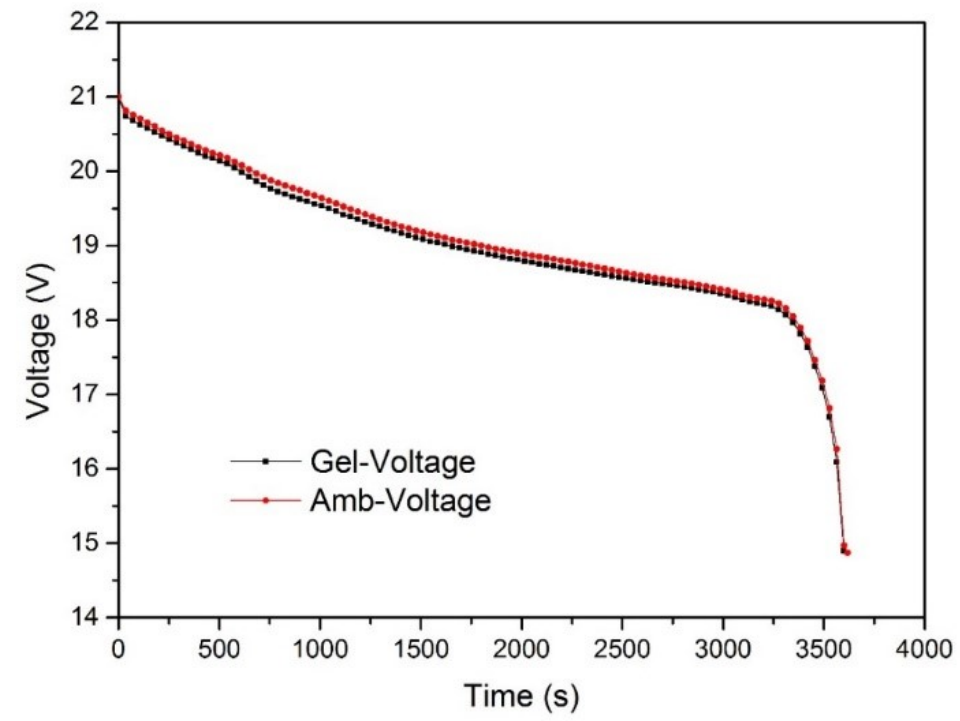

Figure 3.11 Discharge voltage curves of the $2^{\text {nd }}$ cycle of the battery packs in ambient and in hydrogel BTM system.

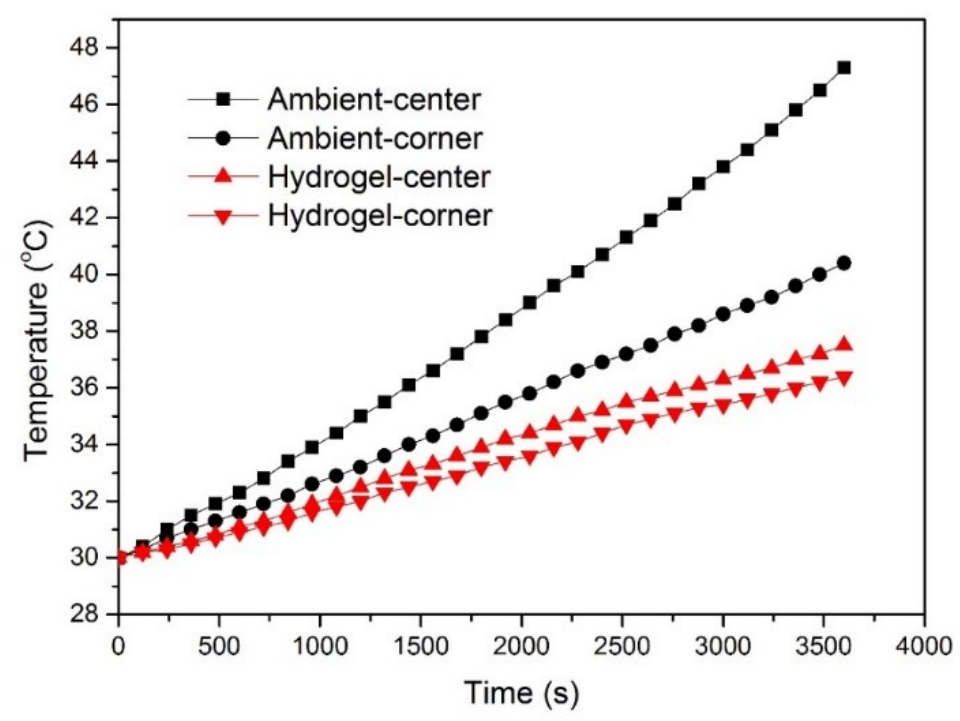

Figure 3.12 Temperature profiles of the $2^{\text {nd }}$ discharge process of the battery packs w/wo hydrogel BTM system. 
In addition, a larger temperature difference inside the battery pack is observed in ambient $\left(7^{\circ} \mathrm{C}\right)$ than in the hydrogel $\mathrm{BTM}$ system $\left(1.1^{\circ} \mathrm{C}\right)$. As discussed in previous section, the increase in temperature difference will accelerate the capacity fading of the whole battery pack.

Finally, as seen from the 300-cycle test results shown in Fig. 3.13, the fading rate of the battery pack using hydrogel BTM system is greatly slower than that without BTM system, and the final discharge capacity of the two battery packs w/wo hydrogel BTM system are $7344 \mathrm{mAh}$ and $6177 \mathrm{mAh}$, which account for $91.8 \%$ and $77.2 \%$ of the nominal capacity, respectively, and the corresponding fading rates are $2.19 \mathrm{mAh} / \mathrm{cy}$ and 6.08 $\mathrm{mAh} / \mathrm{cy}$ in two battery packs.

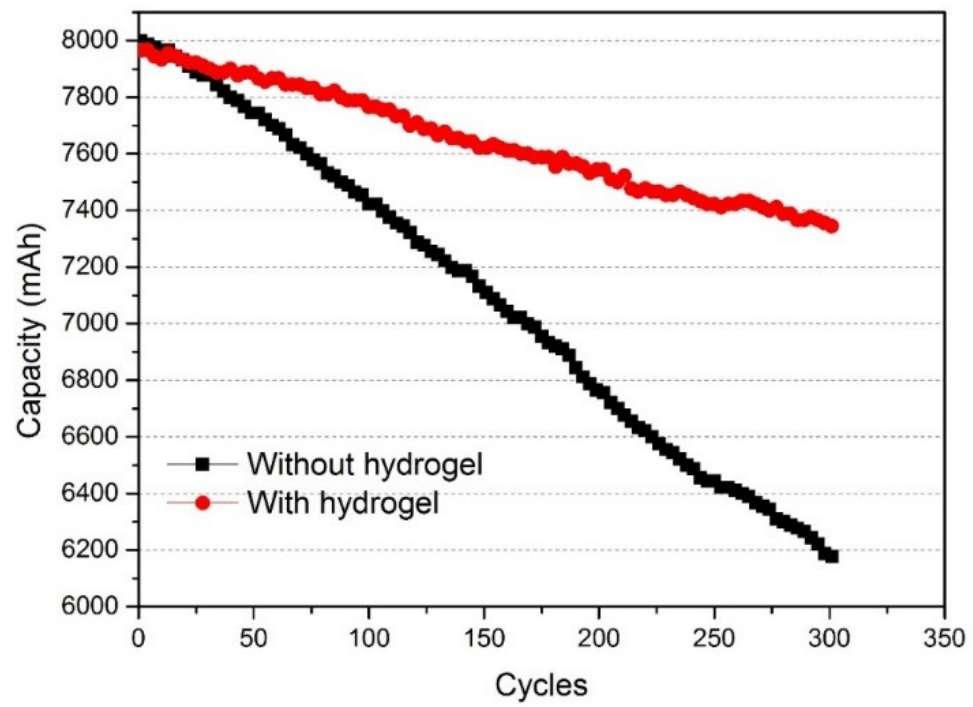

Figure 3.13 Capacity fading curves of the $5 \mathrm{~S} 8 \mathrm{Ah}$ battery packs in ambient condition and in hydrogel BTM system. $\left(\mathrm{T}_{\mathrm{amb}} \mathbf{3 0} \mathbf{0}^{\circ} \mathrm{C}, \mathrm{I}_{\text {discharge }}=\mathrm{I}_{\text {charge-max }}=8 \mathrm{~A}\right)$. 


\subsection{Summary}

A PAAS hydrogel based passive BTM system is developed in this chapter. Water is easy to access, inexpensive and possesses various thermal advantages that can be used to absorb and dissipate heat. Considering the high moisture content of PAAS hydrogel and the water evaporation issue associated to it, an open structure and a closed structure are developed to tackle the mass decrease and humidity problems during the use of hydrogel BTM system. And the possible small volume expansion of hydrogel in cold environment is addressed by leaving a small void space inside the pack or adding ethylene glycol into the hydrogel, which have both been successfully used in previous studies.

The advantage of using the novel hydrogel BTM system over conventional cooling systems is demonstrated by a series of experimental tests. Compared to the hydrogel BTM system, forced air cooling method performs less effective in battery temperature control at high current discharge tests since its heat dissipation rate cannot increase with the heat generation rate of the battery pack. And the power consumption of active air-cooling is usually not ignorable. PCM BTM system has only modest effect during the whole test, and the reasons for that are given from both specific heat capacity and heat conductivity perspectives.

Short term and long term cycling tests are then carried out with the Li-ion battery packs with and without the developed hydrogel BTM system implemented. From the simulation and experimental results for the constant current discharge tests at different rates, the PAAS hydrogel cooling system is capable of maintaining the battery temperature within a desirable range, and a more uniform temperature distribution across the whole battery pack can also be achieved by implementing the developed system. In the continuous 
cyclic safety test, the battery pack using hydrogel BTM system operates stably at all times and completes the entire four cycles successfully, while the one without hydrogel stops early since the temperature reaches the preset limit. Additionally, it is proved by the capacity fading test that the developed hydrogel system can also help alleviate the capacity fading of Li-ion battery in the long run. 


\section{Chapter: Evaluation of Hydrogel Thermal Management System under Abuse Condition}

Bullet penetration is one of the major risks that should be considered when designing the battery pack configuration and its BTM system that will be used in soldier-carried backpacks and military vehicles. In this chapter, nail penetration tests are performed on Liion battery cells equipped with hydrogel and other BTM systems. Through these abusive tests, the capability of the developed PAAS hydrogel based BTM system in preventing the thermal runaway of batteries is demonstrated.

\subsection{Experimental}

The nail penetration test is one of the most common abuse tests of Lithium-ion battery cells. It simulates the internal short-circuit (ISCr) of batteries and has been widely used across the Li-ion battery industry to assess battery safety. In this study, penetration tests were conducted on $8000 \mathrm{mAh}$ Lithium-ion battery cells. The cells were preconditioned under constant current of $0.1 \mathrm{C}$ between $3.0 \mathrm{~V}$ and $4.2 \mathrm{~V}$, and finished at charged state prior to the tests. Each charged sample cell was then encased in a container of $20 \mathrm{~cm} \times 6.5 \mathrm{~cm} \times$ $5.5 \mathrm{~cm}$. Depending on the thickness of the coolants used in the container, the testing systems were divided into "heavy system (HS)" and "light system (LS)" as schematically shown in Figs. 4.1a and 4.1b, respectively. The small blocks in the figures represent the wood brackets which are able to secure the cells during the tests. The PCM, water and hydrogel were employed as coolants during tests, and the thickness of the coolants on either side of the cell was $2 \mathrm{~cm}$ and $1 \mathrm{~cm}$ in HS and LS, respectively. For accuracy, a total of 
three cells were penetrated for each testing system, and the reproducibility has been found to be good. The ambient temperature was $15^{\circ} \mathrm{C}$ during the tests.
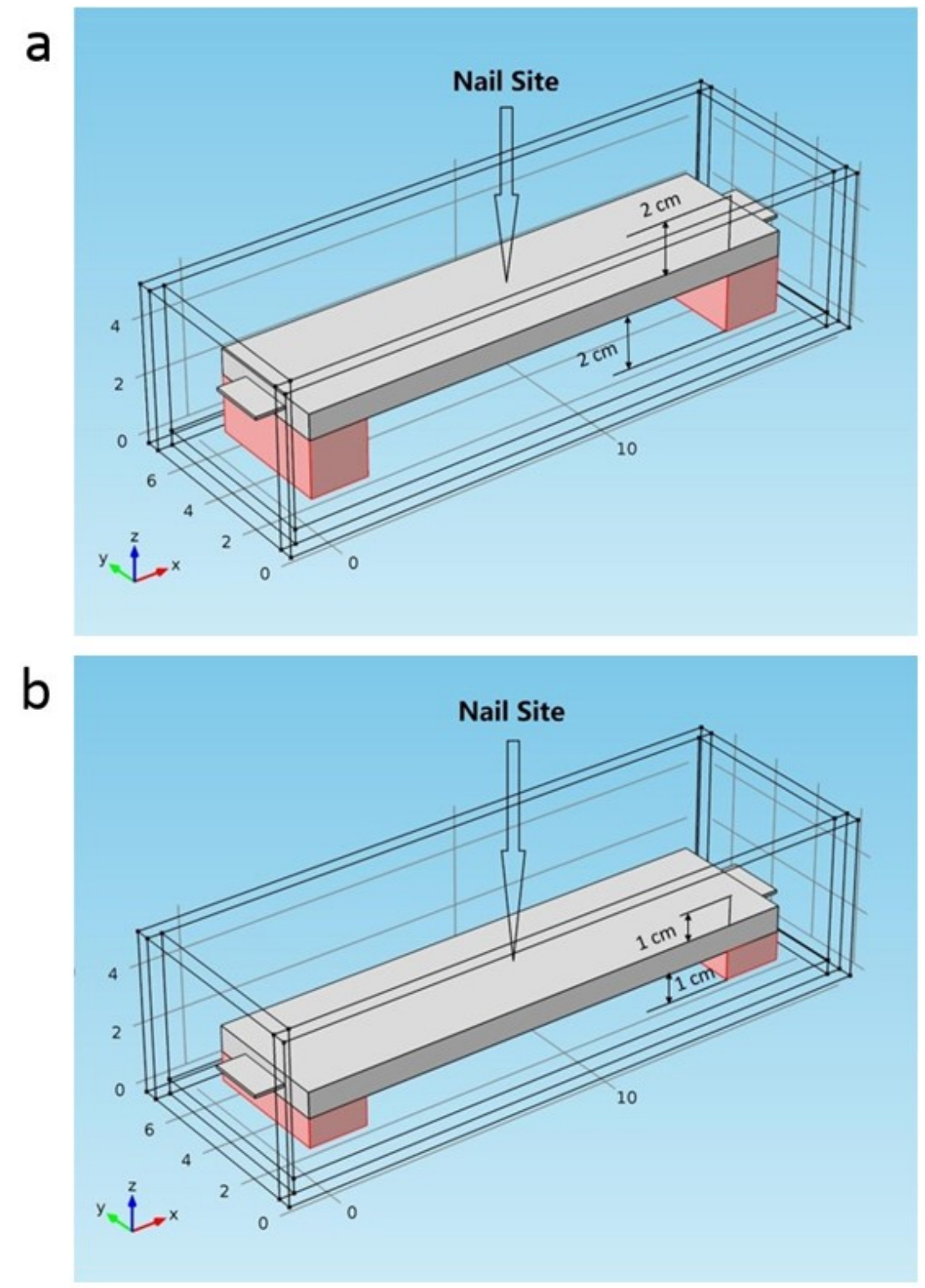

Figure 4.1 Schematic illustration of two penetration systems: (a) heavy system and (b) light system.

Based on the nail type and coolant, six groups of tests were carried out in either the HS or LS, which are summarized in Table 7. The nail type 1 and 2 represent the hardwood 
$(R>60 \mathrm{M} \Omega)$ and steel $(R=0.2 \Omega)$ nail of $3 \mathrm{~mm}$ diameter, respectively. During each test, the penetrating process was performed and then followed by a retracting procedure. In addition, a digital voltmeter and an infrared thermometer were used during the tests to measure the voltages and temperatures of the cells, respectively.

Table 7. List of information on experimental groups.

\begin{tabular}{lccll}
\hline Test number & Battery size $\left(\mathrm{cm}^{3}\right)$ & Nail type & Protection system & HS or LS \\
\hline 1 & & 2 & Ambient & HS \\
2 & 1 & Ambient & HS \\
3 & $17.5 \times 4.5 \times 0.9$ & 2 & PCM & HS \\
4 & 2 & Water & HS \\
5 & 2 & Hydrogel & HS \\
6 & 2 & Hydrogel & LS \\
\hline
\end{tabular}

\subsection{Results and Discussions}

In this experimental study, a series of penetration tests have been conducted to verify the capability of the developed PAAS hydrogel based BTM system in handling an extreme condition (i.e., battery thermal runaway) that may occur in real-world applications. In the first round, four groups of tests were conducted. Test Group \#1 and \#2 were designed to compare the level of risks that may be incurred by two types of nails, hardwood nails and steel nails that respectively represent insulating penetrators and conducting penetrators. These two groups of tests were performed at an ambient temperature $\left(15^{\circ} \mathrm{C}\right)$. The tests revealed that the involved cells bulged with an intensive venting and the surface 
temperature experienced a dramatic increase and exceeded $500^{\circ} \mathrm{C}$. As an example, a popped cell penetrated by a hardwood nail is shown in Fig. 4.2. Unpacking the damaged cells, the deformations around the penetrated holes were observed, and also the anodes were found in touch with the adjacent cathodes, which caused serious ISCr. It is believed that the large current caused by ISCr led to a dramatic temperature rise, which in turn initiated the thermo-chemical chain reactions of the electrolyte, electrodes, and separators within each battery cell, thereby generating a huge amount of heat $[49,50]$. It was also observed that the response time (i.e., the time interval between nailing and cell popping) caused by steel nails was about $2 \mathrm{~s}$, which is much shorter than the $10 \mathrm{~s}$ response time caused by hardwood nails, due to the relatively much higher electric conductivity of the steel. As such, more testing has been done in the following experiments (i.e., Group Tests $\# 3$ - \#6) with the steel nailing to compare the performance of the PAAS hydrogel and other protection systems in suppressing battery thermal runaway. 


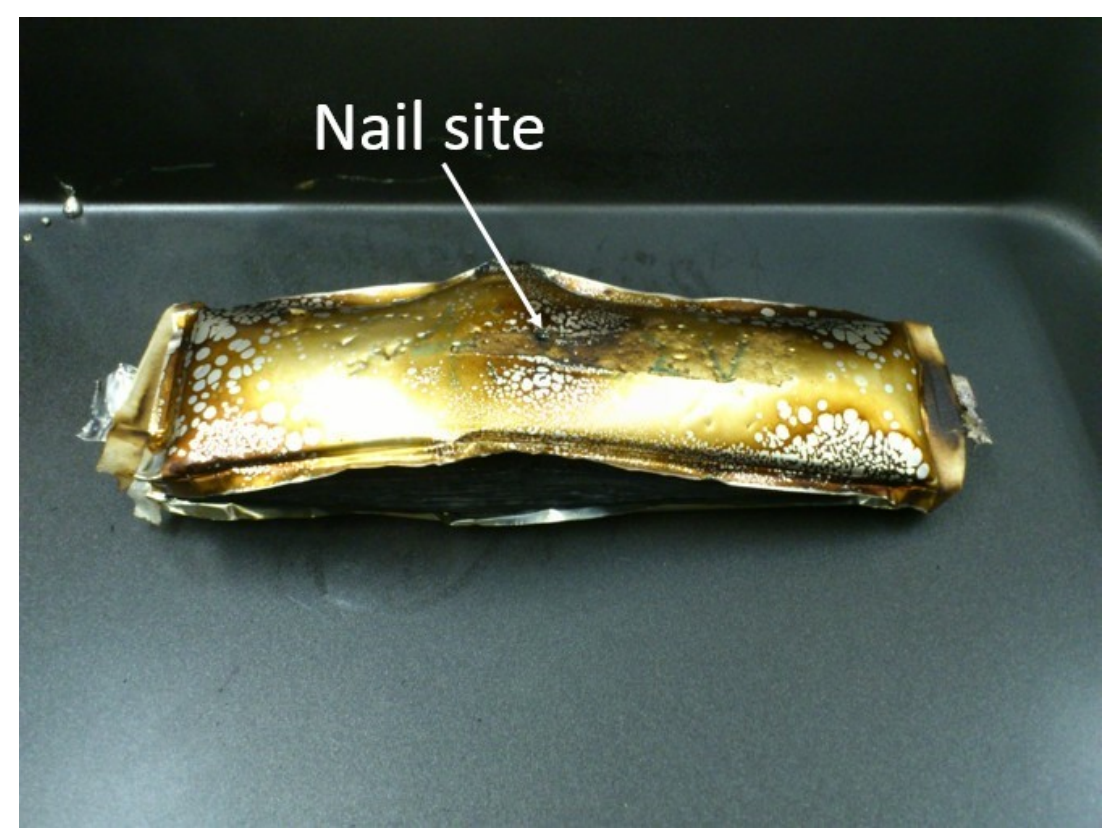

Figure 4.2 Photograph of a seriously damaged cell penetrated by a wooden nail.

The traditional PCM was employed in Group Test \#3 for handling the battery thermal runaway, where the test cells were fastened at the center of the container with $2 \mathrm{~cm}$ PCM stacked on both sides (i.e., the HS as shown in Fig. 4.1a). When the cells were penetrated, they immediately experienced a severe thermal runaway. The intensive venting and the sudden deformation of the cells pushed the top layer of PCM out of the container. The surface temperatures of the cells were measured to be over $450^{\circ} \mathrm{C}$. Meanwhile, the bottom layer of PCM melted down as a result of the high temperature and huge heat accumulation. It is experimentally found that the traditional PCM is not effective in preventing the battery thermal runaway in this battery penetration test.

Considering water is the major component (in terms of wt.\%) of the developed PAAS hydrogel based BTM system, Group Test \#4 only applied water in the HS to evaluate its viability in preventing the occurrence of thermal runaway. In this testing, the positive and 
negative electrodes of the cells were sealed before immersing them into the water. Immediately after the nails were retracted from the cells, bubbles were continuously generated from the nailed hole at an increasing speed. In about 5 to $10 \mathrm{~s}$, white smoke were generated from the test cells and the cells then severely vented and popped, as similarly seen from the penetration tests in ambient conditions. However, the surface temperatures of the test cells remained below $150^{\circ} \mathrm{C}$, compared to over $500^{\circ} \mathrm{C}$ in the ambient testing case. The testing results from the Group Test \#1 - \#4 are summarized in Table 8.

Table 8. Summary of Li-ion battery testing results in Test 1-4.

\begin{tabular}{llllll}
\hline Test No. & Voltage before & Voltage after & No. of & Maximum & No. of \\
& penetration & penetration & cells & surface & cells \\
& (V) & $(\mathrm{V})$ & tested & temperature $\left({ }^{\circ} \mathrm{C}\right)$ & vented \\
\hline 1 & 4.15 & 0 & 3 & $>500$ & 3 \\
3 & 4.15 & 0 & 3 & $>350$ & 3 \\
4 & 4.15 & 0 & 3 & $>450$ & 3 \\
\hline
\end{tabular}

The testing results from the Group Test \# 3 (PCM) and \#4 (water) were served as the benchmarks for the subsequent testing in Group Test \#5 (PAAS hydrogel in HS) and \#6 (PAAS hydrogel in LS) to verify the effectiveness of the developed hydrogel based BTM system in battery thermal runaway suppression. In Group Test \#5, the PAAS hydrogel (2 wt.\%) was injected into the HS as the thermal management material. In contrast to the severe reactions that occurred in Group Test \#4 (water), all of the tested three cells in Group 
Test \#5 (immerged in hydrogel) passed the penetration testing without incurring thermal runaway (even no venting). Table 9 summarizes the testing results. As an example, Figure 4.3 shows one cell with two nailing holes. After penetration, the voltages of two cells dropped to $0 \mathrm{~V}$ after $12 \mathrm{~h}$. For further performance validation, a third nailing was performed on the third tested cell in which the hydrogel has been completed dumped; the cell quickly went to venting. These testing results demonstrate the effectiveness of the developed PAAS hydrogel in maintaining the stability of the Li-ion battery cells under nail penetration.

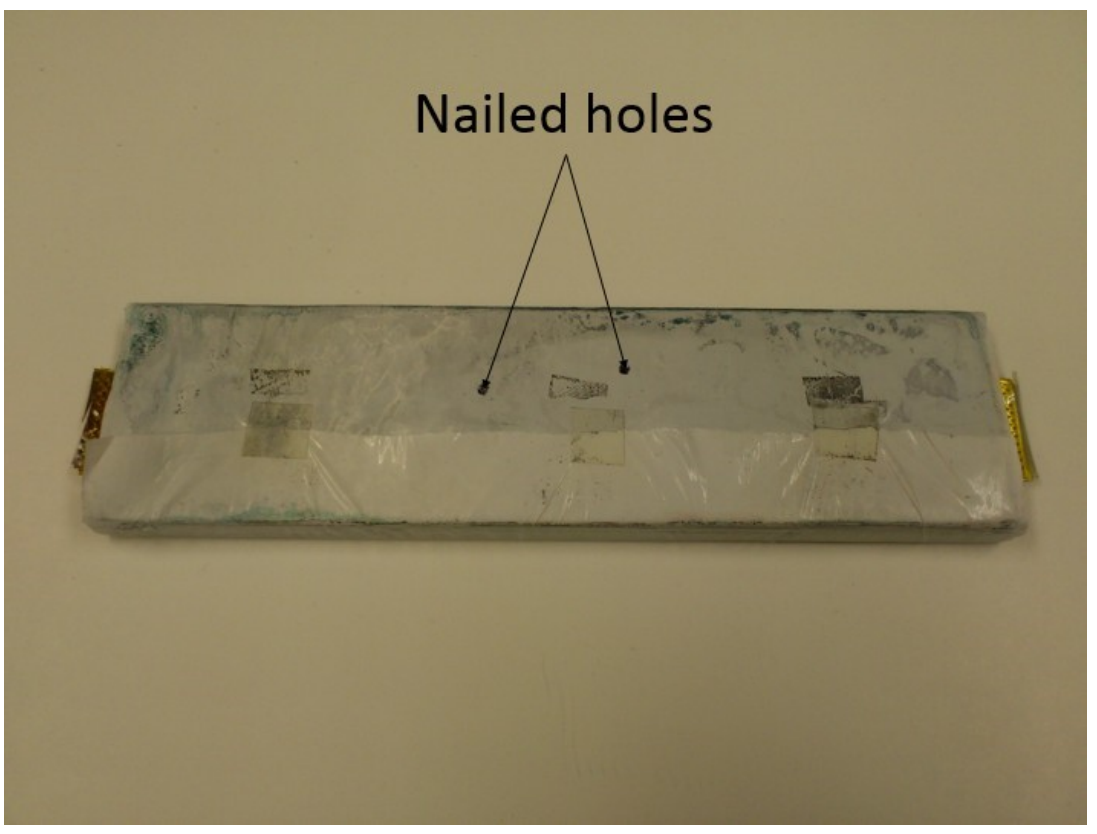

Figure 4.3 Photograph of a sample cell penetrated in hydrogel BTM system.

To physically understand this finding, Figure 4.4 depicts the motion of ions and electrons between adjacent electrodes when a cell is nailed. With the separator as the barrier, the electrons can only migrate in the nailing region, which leads to a higher current density, and more heat will then be generated locally. If the excessive thermal heat cannot be dissipated efficiently, the dramatic temperature rise will cause the separators around the 
nailing holes to shrink, thereby leading to more severe ISCr. Both the hydrogel and water have the capability to cool down the cells, but the difference in their viscosities can lead to significantly different performances. After the cells being penetrated, a certain amount of fumes are generated due to internal thermo-chemical reactions, which creates a high pressure inside the nailing hole that in turn blows the coolant (either hydrogel or water) out. Due to its much lower viscosity, water is more susceptible to be blown away, and this is the reason why the temperature in the nailing region of the water based HS increases dramatically in the cell penetration tests. Furthermore, the electrical resistance of hydrogel is usually 15 times of that of water with electrodes immersed, which leads to much less heat generation under the same ISCr circumstance. 
Table 9. Penetration results for the cells tested in the hydrogel thermal management system.

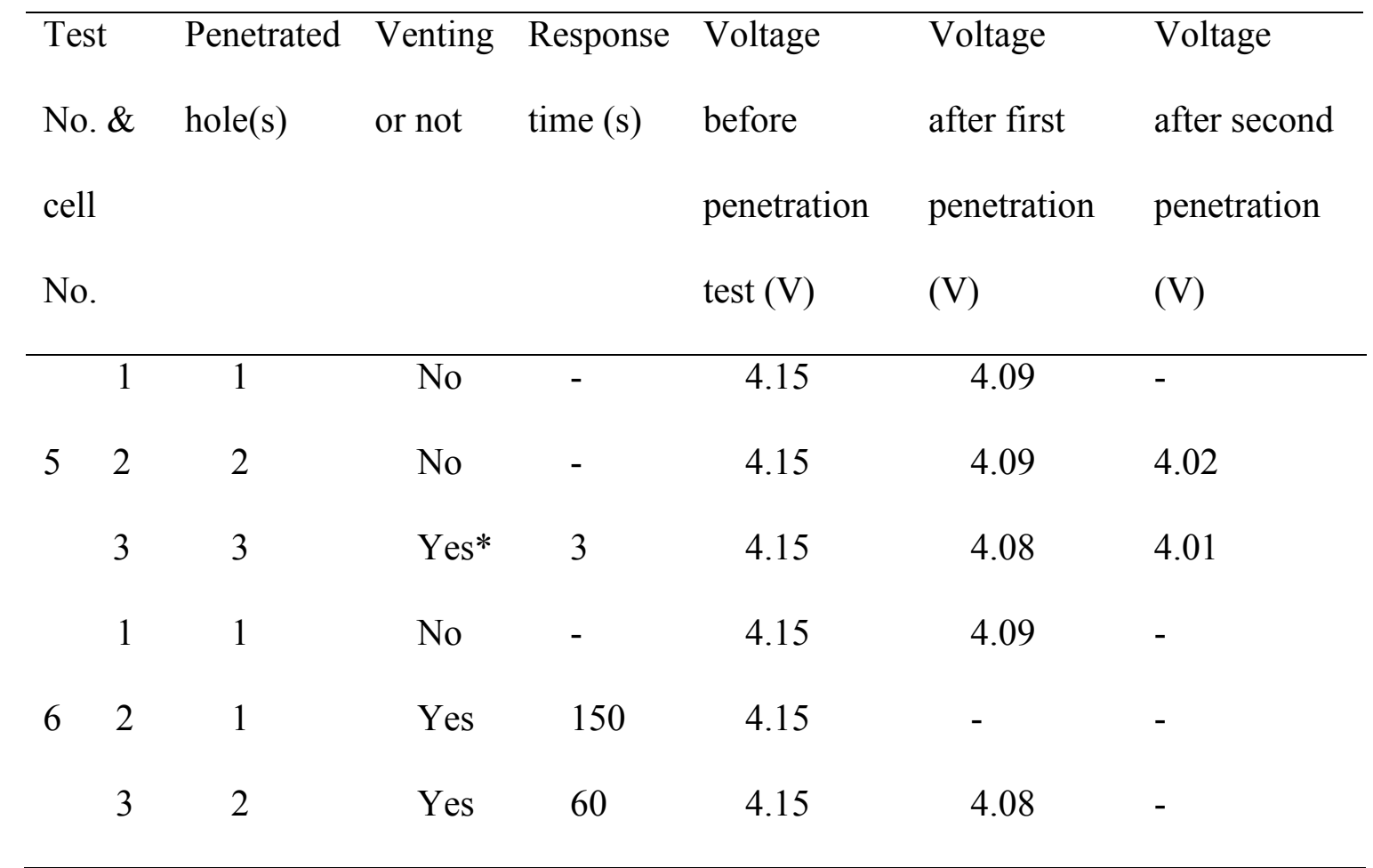

* Venting took place at the third penetration without the protection of hydrogel thermal management system.

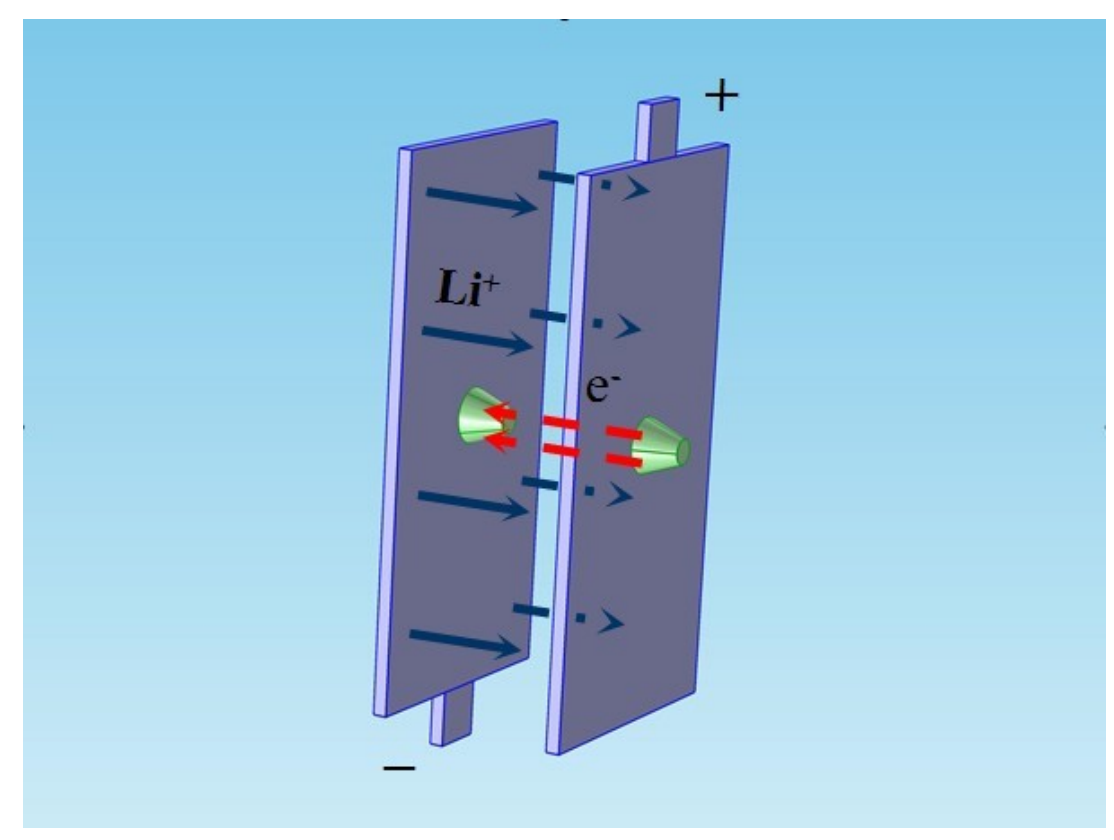

Figure 4.4 Schematic diagram of the motion of ions and electrons in adjacent electrodes after 


\section{penetration.}

For comparison with the testing results from Group Test \#5 (HS), Group Test \#6 applied hydrogel in the LS setting. As summarized in Table 9, three cells were tested. Among them, one cell did not vent and its voltage gradually dropped to $0 \mathrm{~V}$ after $12 \mathrm{~h}$. The other two cells went on venting with the response time to be $150 \mathrm{~s}$ and $60 \mathrm{~s}$, respectively. The testing results indicate that a lower amount of hydrogel will correspondingly reduce the level of protection in battery thermal runaway. This is because the less hydrogel provides a lower pressure on the battery surface that is insufficient to balance the pressure generated inside the nailing hole caused by the cell internal chemical reaction. Moreover, when the cell is nailed, a longer time is required for the hydrogel in LS to enter the nailed holes to insulate the electrodes and control the temperature rise, so the increased temperature may still be able to initiate some internal reactions.

\subsection{Summary}

Lithium ion battery cells equipped with different protection systems are tested under abuse condition. The objective is to observe the effects of different BTM systems in controlling the heat surge and thermal runaway of Li-ion battery penetrated by nails, as discussed below:

1) Both hardwood nail and steel nail can cause ISCr and intensive venting of Li-ion battery cells. But due to the relatively higher electric conductivity of steel, the cells penetrated by steel nails pop much faster after the penetration than the ones penetrated by hardwood nails. 
2) Because excessive heat is produced in the battery cell immediately after the penetration, both PCM and water, which are "too fixed" and "too mobile", respectively, are not able to prevent the venting of the nailed batteries. The phase change of PCM from solid to liquid state needs a period of time, while water is too easy to be popped out when vast amount of gas is generated.

3) PAAS hydrogel shows to be very effective in maintaining the stability of Li-ion battery cells after nail penetration. With moderate mobility and viscosity, the hydrogel can help alleviate and even eliminate the heat surge caused by penetration, especially when large amount is applied. 


\section{Chapter: Conclusions and Future Works}

This chapter reviews the PAAS hydrogel BTM system developed in this study and the main results obtained from all the effectiveness tests. Furthermore, what will be done in the next stage of work are also listed.

\subsection{Conclusions}

A thermal management system for Lithium-ion battery pack is often desired to possess the following properties: space saving, energy efficient, easy to manufacture, and low cost. More importantly, it should be able to maintain the temperature of the battery pack in an appropriate range and minimize the temperature difference inside the battery pack. In this work, a study on implementing a novel hydrogel based passive cooling system for Li-ion battery thermal management is carried out. The effectiveness of the hydrogel based BTM system in heat dissipation is validated in both the normal discharge processes and the nail penetration tests. Based on the high moisture content, the hydrogel based BTM system keeps most advantages of water (i.e., high specific heat capacity and medium heat conductivity) and in the meantime the mobility of water is prevented. In discharge tests, the developed hydrogel BTM system shows its effectiveness in dissipating the heat generated from the battery packs without requiring an additional power supply. Some concluding remarks are summarized below:

(1) The developed hydrogel BTM system demonstrates its advantages over conventional forced air cooling method and traditional PCM passive cooling method in the 
discharging tests carried out with Li-ion batteries of different capacities.

(2) During the high rate constant current discharge test, the temperature variation trend and distribution from the simulation have a good agreement with the experimental results, which proves that the heat from the internal resistance predominates during battery discharge at high rates and provides a brief simulation for battery at high rate discharge.

(3) Both the simulation and experimental results at a high discharge rate $(10 \mathrm{~A})$ demonstrate the excellent performance of the hydrogel BTM system in decreasing the temperature rise and minimizing the temperature difference inside the battery pack.

(4) Experimental results for four discharge rates further validate the effectiveness of the hydrogel in controlling the temperature rise and reducing the temperature difference inside the battery pack.

(5) The continuous charge/discharge safety test shows that the battery pack without BTM system has potential safety risks posed by the high temperature, whereas can be kept in a safe operational temperature range during the whole test when the hydrogel is implemented.

(6) Battery pack equipped with the hydrogel BTM system exhibits a lower capacity fading rate $(2.19 \mathrm{mAh} / \mathrm{cy})$ compared to the high fading rate $(6.08 \mathrm{mAh} / \mathrm{cy})$ of the battery pack in ambient condition.

The advantage of hydrogel BTM system in dealing with extreme conditions is also tested through a series of nail penetration tests. Relying on its high resistance, moderate viscosity and high specific heat capacity, the developed hydrogel based BTM system can either extend the safety time or prevent the occurrence of thermal runaway, and the voltages of the battery cells after the penetration testing can still remain at a high level. 
As a final note, the developed hydrogel based BTM system is targeted to stationary or mobile battery packs that require a compact, accessible, and power-saving cooling system to suppress the unexpected thermal surge or runaway under normal and extreme conditions. This BTM system can be implemented in an open or a closed structure to address the problems associated with evaporation, humidity and volume change during phase change. Meanwhile, a PAAS hydrogel consisting of the water-ethylene glycol mixture would be suggested to prevent the hydrogel from icing at sub-zero temperatures.

\subsection{Future Works}

At this stage, a PAAS hydrogel based passive BTM system has been developed and some preliminary feasibility and functionality validation tests have been conducted with desirable results obtained. Nevertheless, there are still many challenges that need to be addressed in order to further promote the developed hydrogel as a competitive BTM system used in Li-ion battery industry and to resolve other thermal issues associated with the battery. These works can be conducted on the following subjects:

(1) Customization. Li-ion battery has been widely utilized in various areas such as mobile phone, HEV, and aerospace. The batteries used in different applications have dramatically different volume, mass, heat generation rate, working environment and may meet different abusive conditions. Correspondingly, their thermal management demands are different and a "one-size" hydrogel system is not suitable for every single application. Therefore, the packaging of the hydrogel BTM system will be made varied in shape, size, 
packaging material and other aspects to meet the different requirements of different battery systems.

(2) Control and automation. The operating environment and state of health can influence the thermal behavior of a battery system, which will affect the heat generation rate and heat distribution in the battery cells during operation. An automatic control system will be added to detect the temperature at different regions of the battery pack and adjust the amount of hydrogel applied accordingly.

(3) New application areas. In addition to battery, there are plenty of electrical and mechanical devices that need efficient heat dissipation. In the next stage, the use of PAAS hydrogel thermal management system in other fields will be explored.

(4) Heating system. In some cold countries, where the temperature can be lower than $-20^{\circ} \mathrm{C}$ in winter, a heating system, instead of a cooling one, should be developed to provide a favorable operating environment for Li-ion battery. The advantageous properties of different battery cooling systems will be used in developing such a heating system. 


\section{Bibliography}

[1] V. Etcheri, R. Marom, R. Elazari, G. Salitra, D. Aurbach. "Challenges in the development of advanced li-ion batteries a review". Energy \& Environmental Science 4, pp. 3243-3262, 2011.

[2] R. Zhao, S. Zhang, J. Gu, J. Liu. “An experimental study of lithium ion battery thermal management using flexible hydrogel films”. Journal of Power Sources 255, pp. 29-36, 2014.

[3] C. Park, A.K. Jaura. "Reciprocating battery cooling for hybrid and fuel cell vehicles". International Mechanical Engineering Congress and Exposition, Washington, 2003.

[4] S. Zhang, R. Zhao, J. Liu, J. Gu. "Investigation on a hydrogel based passive thermal management system for lithium ion batteries”. Energy 68, pp. 854-861, 2014.

[5] J. Wang, P. Liu, J. Hicks-Garner, E. Sherman, S. Soukiazian, M. Verbrugge, H. Tataria, J. Musser, P. Finamore. "Cycle-life model for graphite-LiFePO 4 cells". Journal of Power Sources 196, pp. 3942-3948, 2011.

[6] C. Park, A.K. Jaura. "Dynamic thermal model of Li-Ion battery for predictive behavior in hybrid and fuel cell vehicles". SAE technical paper 2003-01-2286.

[7] R.B. Wright, J.P. Christophersen, C.G. Motloch, J.R. Belt, C.D. Ho, V.S. Battaglia, J.A. Barnes, T.Q. Duong, R.A. Sutula. "Power fade and capacity fade resulting from cycle-life testing of advanced technology development program lithium-ion batteries”. Journal of Power Sources 119-121, pp. 865-869, 2003.

[8] X.M. Xu, R. He. "Research on the heat dissipation performance of battery pack based on forced air cooling”. Journal of Power Sources 240, pp. 33-41, 2013. 
[9] M.R. Giuliano, A.K. Prasad, S.G. Advani. "Experimental study of an air-cooled thermal management system for high capacity lithium-titanate batteries". Journal of Power Sources 216, pp. 345-352, 2012.

[10] Z. Zhang, L. Jia, N. Zhao, L. Yang. "Thermal modeling and cooling analysis of highpower lithium ion cells". Journal of Thermal Science 20, pp. 570-575, 2011.

[11] G. Eggen, G.Vangsnes, "Heat pump for district cooling and heating at Oslo Airport Gardermoen”. The 8th IEA Heat Pump Conference, Las Vegas, 2005.

[12] S.C. Kim, J.P. Won, Y.S. Park, T.W. Lim, M.S. Kim. "Performance evaluation of a stack cooling system using $\mathrm{CO}_{2}$ air conditioning system in fuel cell vehicles". International Journal of Refrigeration 32, pp. 70-77, 2009.

[13] D.Y. Lee, C.W. Cho, J.P. Won, Y.C. Park, M.Y. Lee. "Performance characteristics of mobile heat pump for a large passenger electric vehicle". Applied Thermal Engineering 50, pp. 660-669, 2013.

[14] H. Park. "A design of air flow configuration for cooling lithium ion battery in hybrid electric vehicles". Journal of Power Sources 239, pp. 30-36, 2013.

[15] L. Fan, J.M. Khodadadi, A. Pesaran. "A parametric study on thermal management of an air-cooled lithium-ion battery module for plug-in hybrid electric vehicles”. Journal of Power Sources 238, pp. 301-312, 2013.

[16] K. Chen, X. Li. "Accurate determination of battery discharge characteristics-A comparison between two battery temperature control methods". Journal of Power Sources 247, pp. 961-966, 2014.

[17] S. Al-Hallaj, J.R. Selman. "A novel thermal management system for electric vehicle batteries using phase-change material". Journal of The Electrochemical Society 147, 
pp. 3231-3236, 2000.

[18] A. Pesaran. "Battery thermal models for hybrid vehicle simulations". Journal of Power Sources 110, pp. 377-382, 2002.

[19] P. Ramadass, B. Haran, R. White, B.N. Popov. "Capacity fade of Sony 18650 cells cycled at elevated temperatures: part II. Capacity fade analysis". Journal of Power Sources 112, pp. 614-620, 2002.

[20] R. Kizilela, R. Sabbaha, J. R. Selmana, S. Al-Hallaj. "An alternative cooling system to enhance the safety of Li-ion battery packs". Journal of Power sources 194, pp. 11051112, 2009.

[21] S.G. Jeong, O. Chung, S. Yu, S. Kim, S. Kim. "Improvement of the thermal properties of Bio-based PCM using exfoliated graphite nanoplatelets". Solar Energy Materials and Solar Cells 117, pp. 87-92, 2013.

[22] D. Linden, T.B. Reddy. "Handbook of batteries, third edition". McGraw-Hill, 2002.

[23] P. Taheri, M. Yazdanpour, M. Bahrami. "Transient three-dimensional thermal model for batteries with thin electrodes”. Journal of Power Sources 243, pp. 280-289, 2013.

[24] D. Goughty, E.P. Roth. "A general discussion of Li ion battery safety". The Elctrochemical Society Interface 2012.

[25] L. Fan, J.M. Khodadadi, A.A. Pesaran. "A parametric study on thermal management of an air-cooled Lithium-ion battery module for plug-in hybrid electric vehicles". Journal of Power Sources 238, pp. 301-312, 2013.

[26] X. Zhang, X. Kong, G. Li, J. Li. "Thermodynamic assessment of active cooling/heating methods for Lithium-ion batteries of electric vehicles in extreme conditions". Energy 64, pp. 1092-1101, 2014. 
[27] S. Al-Hallaj, J.R. Selman. "A novel thermal management system for electric vehicle batteries using phase change material". Journal of The Electrochemical Society 147(9), pp. 3231-3236, 2000.

[28] S.A. Khateeb, S. Amiruddin, M. Farid, J.R. Selman, S. Al-Hallaj. "Thermal management of Li-ion battery with phase change material for electric scooters: experimental validation”. Journal of Power Sources 142, pp. 345-353, 2005.

[29] R. Kizilel, A. Lateef, R. Sabbah, M.M. Farid, J.R. Selman, S. Al-Hallaj. "Passive control of temperature excursion and uniformity in high-energy Li-ion battery packs at high current and ambient temperature". Journal of Power Sources 183, pp. 370-375, 2008.

[30] T.H. Tran, S. Harmand, B. Desmet, S. Filangi. "Experimental investigation on the feasibility of heat pipe cooling for HEV/EV Lithium-ion battery". Applied Thermal Engineering 63, pp. 551-558, 2014.

[31] Z. Rao, S. Wang, M. Wu, Z. Lin, F. Li. "Experimental investigation on thermal management of electric vehicle battery with heat pipe". Energy Conversion and Management 65, pp. 92-97, 2013.

[32] D. Bernardi, E. Pawlikowski, J. Newman. "A general energy balance for battery systems". Journal of The Electrochemical Society 132, pp. 5-12, 1985.

[33] B. Wu, V. Yufit, M. Marinescu, G.J. Offer, R.F. Martinez-Botas, N.P. Brandon. "Coupled thermal-electrochemical modelling of uneven heat generation in Lithiumion battery packs". Journal of Power Sources 243, pp. 544-554, 2013.

[34] C. Alaoui. "Solid-state thermal management for Lithium-ion EV batteries". IEEE Transaction Vehicle Technology 62, pp. 98-107, 2013. 
[35] K. Smith, C.Y. Wang. "Power and thermal characterization of a Lithium-ion battery pack for hybrid-electric vehicles". Journal of Power Sources 160, pp. 662-673, 2006.

[36] Y. Chen, J.W. Evans. "Heat transfer phenomena in lithium/polymer-electrolyte batteries for electric vehicle application”. Journal of the Electrochemical Society 140, pp. 1833-1838, 1993.

[37] S.C. Chen, C.C. Wan, Y.Y. Wang. "Thermal analysis of Lithium-ion batteries". Journal of Power Sources 140, pp. 111-124, 2005.

[38] G.F. Hewitt, G.L. Shires, T.R. Bott. "Process heat transfer". CRC Press, London, 1993.

[39] M.J. Moran, H.N. Shapiro, D.D. Boettner, M.B. Bailey. "Fundamentals of engineering thermodynamics, seventh edition”. John Wiley \& Sons, Inc, New York, 2011.

[40] http://www.google.ca/url?sa=t\&rct=j\&q=\&esrc=s\&source=web\&cd=3\&ved=0CEIQ FjAC\&url=http\%3A\%2F\%2Fwww.electrochem.org\%2Fdl\%2Fma\%2F200\%2Fpdfs \%2F0305.pdf\&ei=bTerUvGcC8q0rgGupYHABQ\&usg=AFQjCNH1TpihQYIv4ngF XHRveBusbtvu8w\&sig2=w537PT59kcs78axLoFIGjA, last accessed: 09/07/2013.

[41] J.S. Lee, S. Lucyszyn. "Thermal analysis for bulk-micromachined electrothermal hydraulic microactuators using a phase change material". Sensors and Actuators A: Physical 135, pp. 731-739, 2007.

[42] C.G. Motloch, J.P. Christopheresen, J.P. Belt, R.B. Wright, G.L. Hunt, R.A. Sutula, T.Duong, T.J. Tartamella, H.J. Haskins, T.J. Miller. "High-power battery testing procedures and analytical methodologies for HEV's". SAE 2002-01-1950.

[43] C. W. Park, A.K. Jaura. "Dynamic thermal model of Li-ion battery for predictive behavior in hybrid and fuel cell vehicles". SAE International Journal 112, pp.18351842, 2003. 
[44] S. Franger, C. Benoit, C. Bourbon, F.L. Cras. "Chemistry and electrochemistry of composite LiFePO4 materials for secondary lithium batteries". Journal Physical Chemistry Solids 67, 1338-1342, 2006.

[45] B.V. Ratnakumar, M.C. Smart, J.O. Blosiu, S. Surampudi. "Storage characteristics of lithium ion cells". Proceedings of Electrochemical Society 99-25, pp. 706-18, 2000.

[46] J. Vetter, P. Novák, M. Wagner, C. Veit, K.C. Möller, J. Besenhard, M. Winter, M. Wohlfahrt-Mehrens, C. Vogler, A. Hammouche. "Ageing mechanisms in lithium-ion batteries". Journal of Power Sources 147, pp. 269-281, 2005.

[47] I.J. Fernandez, C.F. Calvillo, A. Sanchez-Miralles, J. Boal. "Capacity fade and aging models for electric batteries and optimal charging strategy for electric vehicles". Energy 60, pp. 35-43, 2013.

[48] K. Amine, J. Liu, I. Belharouak. "High-temperature storage and cycling of C$\mathrm{LiFePO}_{4} /$ graphite Li-ion cells”. Electrochemistry Communications 7, pp. 669-673, 2005.

[49] H. Maleki, J.N. Howard. "Internal short circuit in Li-ion cells". Journal of Power Sources 191, pp. 568-574, 2009.

[50] W. Cai, H. Wang, H. Maleki, J. Howard, E.L. Curzio. "Experimental simulation of internal short circuit in Li-ion and Li-ion-polymer cells". Journal of Power Sources 196, pp. 7779-7783, 2011.

[51] A. Pesaran. "Battery Thermal Management in EVs and HEVs: Issues and Solutions". The Advanced Automotive Battery Conference, Las Vegas, 2001. 